\title{
SCAling UP LOCAl Climate ACTION: A SURVEy OF Climate POLICY PRIORITIES IN The Vancouver Island and Coastal Communities Region
}

\author{
Ekaterina Rhodes $^{\mathrm{a}}$ iD, Tamara Krawchenko ${ }^{\mathrm{a}}$, Katherine Pearce ${ }^{\mathrm{a}}$, Karena Shaw ${ }^{\mathrm{a}}$ \\ ${ }^{\mathrm{a}}$ University of Victoria
}

\begin{abstract}
Résumé
La planification régionale peut aider les communautés fonctionnellement connectées à partager l'expertise et les coûts de l'action climatique et à amplifier les préoccupations et les besoins collectifs des gouvernements de niveau supérieur. La compréhension des impacts climatiques, des politiques et des obstacles à l'action des communautés est fondamentale pour le développement de la planification climatique à l'échelle régionale. À l'appui d'une stratégie climatique naissante dans la région de l'île de Vancouver et des communautés côtières de la Colombie-Britannique, notre étude utilise une enquête en ligne auprès des autorités locales $(\mathrm{n}=106)$. Nous identifions les impacts climatiques existants, les priorités politiques, les barrières et les opportunités qui guident l'élaboration des politiques climatiques dans la région, y compris les impacts de la pandémie COVID19. Nous constatons que presque toutes les communautés ont subi des impacts liés au climat et ont mis en œuvre une variété de politiques climatiques. Cependant, les gouvernements locaux sont confrontés à des obstacles importants - y compris un manque de ressources financières, d'autorité et de capacité en personnel pour poursuivre l'action et la planification climatiques.
\end{abstract}

Mots-clés: planification climatique régionale; priorités de la politique climatique; les barrières de la politique climatique; enquête sur le gouvernement local

\section{Abstract}

Regional planning can help functionally-connected communities share expertise and the costs of climate action and amplify collective concerns and needs to upper-level governments. Understanding communities' climate impacts, policies and barriers to action is foundational to the development of regional-scale climate planning. In support of a nascent climate strategy in the Vancouver Island and Coastal Communities region of British Columbia, our study employs a web-based survey of local government officials $(n=106)$ to identify the existing climate impacts, policy priorities, barriers, and opportunities that guide climate policy-making in the region, including the impacts of the COVID-19 pandemic. We find that nearly all communities have experienced climate-related impacts and have implemented a variety of climate policies. However, local governments face substantial barriers-including a lack of financial resources, authority and staffing capacity_to pursue climate action and planning.

Keywords: regional climate planning; climate policy priorities; climate policy barriers; survey of local government

Canadian Planning and Policy / Aménagement et politique au Canada, Volume 2021, pages 36-69.

This work is licensed under a Creative Commons Attribution 4.0 International License.

ISSN 2562-122X

DOI 10.24908/cpp-apc.v2021i01.14469 


\section{INTRODUCTION}

Global climate change is experienced at a local level (Gupta et al., 2008). Rising global average temperatures cause extreme weather events and changes in weather patterns that affect local land use, water supply, agriculture, fisheries, and other practices. Yet existing community-level governance structures for revenue generation, borrowing, and infrastructure funding constrain climate action plans. For example, community-level greenhouse gas (GHG) emissions are often linked to national and sub-national sectors, limiting municipal authority to reduce their own greenhouse gas (GHG) emissions (Jaccard et al., 1997; Robinson \& Gore, 2005). This discrepancy suggests the potential for partnerships between communities to plan for climate change at a broader regional scale (Coen et al., 2020; Birkmann et al., 2010; Lubik et al., 2020).

Regionally-scaled planning can help communities share essential climate action knowledge in order to better understand and map functionally connected territories (Dale et al., 2020; Tomaney et al., 2019). It can support communities to share the costs of environmental assessments, low-carbon infrastructure procurement, and other upfront planning needs in order to better co-ordinate and scale-up investments in climate change adaptation and mitigation efforts (CIP, 2018; Ledda et al., 2020; OECD, 2017). Mutually supporting communities of all sizes can build capacity to develop consistent climate policy proposals and communicate those to senior levels of government in a common and louder voice (Giest \& Howlett, 2013; Gore, 2010). For these reasons, representatives from municipal governments and regional districts in the Vancouver Island and Coastal Communities (VICC) region in the province of British Columbia have initiated the development of a regional climate plan. VICC communities already share a clear and common vision for a resilient and low-carbon future, suggesting that a regional climate plan can guide action effectively and rapidly (AVICC, 2020).

This is a unique initiative. While regional climate planning presently occurs at a metropolitan or

CIP-ICU \& ACUPP-APUCU regional district scale in some parts of British Columbia, there is no strategy encompassing multiple regional districts; nor are there policy incentives to establish one. BC also has land use, landscape, coastal, and marine plans across resource regions across resource regions: these do not address climate change directly. The VICC climate strategy initiative has been driven by local government leaders and is a form of informal institution-building. Given this, political and civil society momentum in support of a regional climate plan of this scale is important. A strong collective understanding of the various climate impacts, policies, and barriers to climate action across the region is foundational to the development of this collective vision. Given that VICC is not an established administrative unit, information about its communities' climate change impacts and policies is not systematically summarized.

The objective of this study is to support this first step in regional climate planning: it identifies existing climate impacts, policy priorities, barriers, and opportunities that currently guide climate policy -making in the region, including the role of the COVID-19 pandemic. We employed a web-based survey of local government elected officials and staff $(n=106)$ from 38 municipalities and 10 regional districts in the VICC region. Collecting primary survey data from government 'elites' (Sovacool et al., 2018) represents an empirically novel approach to inform regional planning given the emerging research into the importance of public service motivation in shaping policy preferences, budget priorities, and strategic planning processes (Piatak \& Holt, 2021). To our knowledge, this is the first study to systematically explore climate policy preferences and barriers in local governments to inform a regional climate plan. Beyond the academic novelty, original data on local climate policy priorities can help enhance social and political acceptance of climate policy options and their rapid implementation in the VICC region (Goulder \& Parry, 2008). Our study, however, does not test a specific conceptual framework. While we follow Fisher's (2011) guidelines for designing community-level climate policy surveys, we 
primarily employ an exploratory research approach to gather information about existing climate impacts and policy priorities to assess opportunities for regional climate planning.

The study is organized as follows. Section 2 describes the VICC region in terms of its key geographical and socio-demographic characteristics, as well as existing climate plans. Section 3 describes the methodology of our survey data collection and analysis. Section 4 summarizes survey results. Section 5 concludes and discusses the key implications of our findings for regional climate planning and future research.

\section{UNDERSTANDing THE VANCOUVER ISLAND AND Coastal Communities region}

In 2019, three Vancouver Island mayors-Lisa Helps of the City of Victoria, Michelle Staples of the City of Duncan and Josie Osborne of the District of Tofino-convened an ad-hoc group (the Vancouver Island and Coastal Communities Climate Leadership Plan Steering Committee, VICC-CLP), which includes representatives from each of the regional districts on the island and Sunshine Coast. Their collective aim is to produce a plan that will catalyze climate mitigation and adaptation throughout the region. The VICC represents a promising geographical region for regional planning: comprised of island and coastal communities, the region shares a common history, as well as vulnerabilities, adaptation, and mitigation challenges. Its economic diversity and urban-rural linkages offer differential capacities and priorities, supporting the potential for building circular and sustainable economies with shared resources and coordinated action. The region partially corresponds to that of the Association of Vancouver Island and Coastal Communities (AVICC), one of five area associations in BC. The planning process and survey cover the areas of Vancouver Island, the Sunshine Coast, and the smaller islands in between, and includes 40 municipalities and 10 regional districts (Figure 1). The entirety of Vancouver Island and the coastal mainland are the traditional territories of Indigenous peoples, whose relationships with the land continue to the present time.

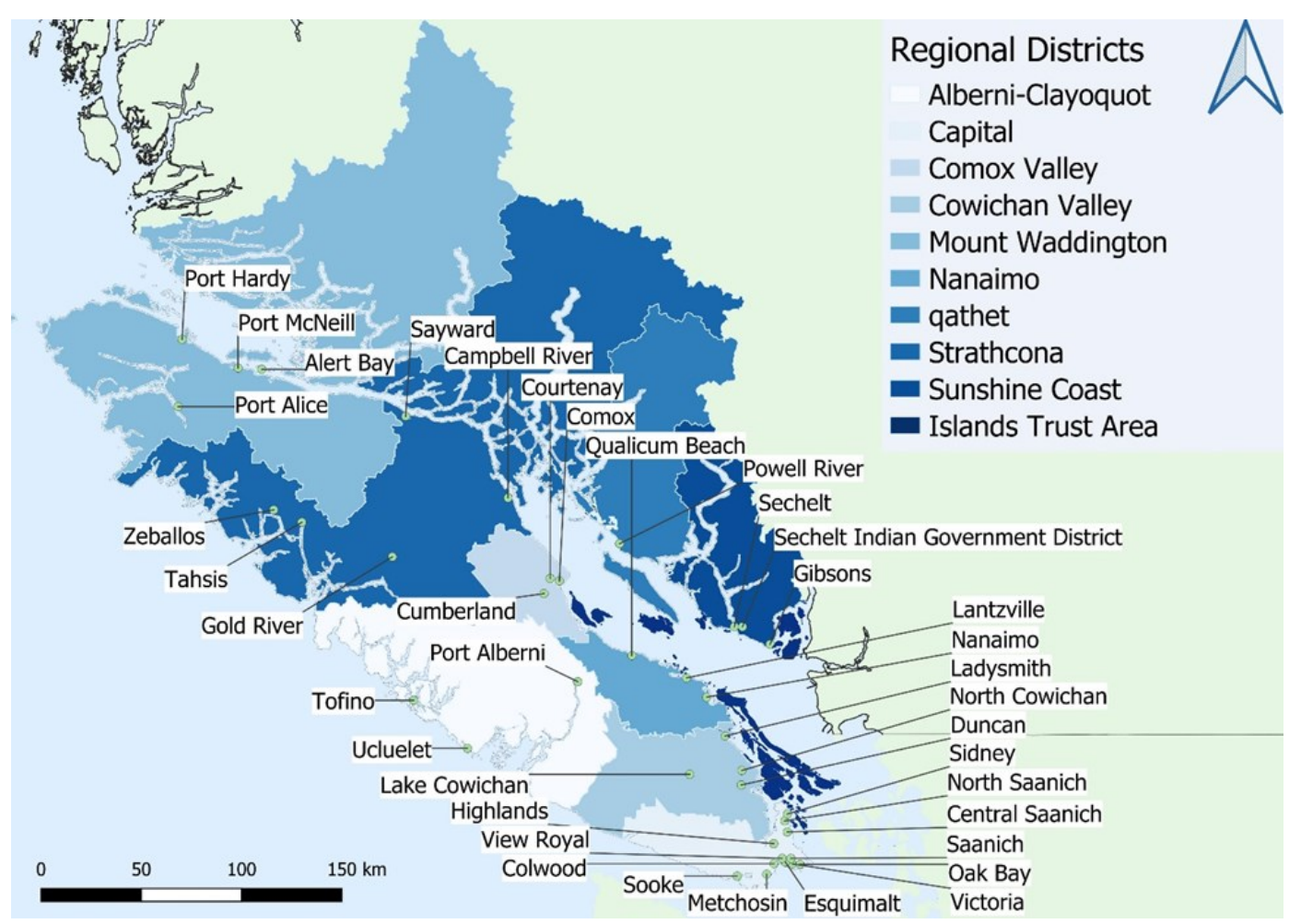

Figure 1. Regional districts and municipalities participating in the survey. 
As a coastal territory, the changes in the ocean due to climate change pose a serious threat to communities within VICC; sea level rise, warmer temperatures, and acidification are of particular concern. Sea level rise-which differs across the territory due to isostatic rebound - is linked to more frequent and severe flooding, salinification of groundwater aquifers and agricultural lands due to saltwater intrusion, increased stress on drainage and sewage systems, and more frequent and severe storms (BC Ministry of Environment, 2016). Warming ocean temperatures harm marine organisms, including fish and shellfish, while ocean acidification is likewise is harmful to marine life. While many of these changes are significant throughout the region, the impacts are not uniform. The global trend of rising surface temperatures also affects the VICC region, and due to the complex geography of the region, there are variations in the average temperature increases, with northern areas experiencing greater increases than southern coastal areas (Krawchenko et al., 2020). Associated effects include increased droughts, more frequent heat waves, increased risk of wildfire, threats to food security and drinking water supplies, and changing habitats for flora and fauna including the relocation of culturally and economically important species. Precipitation patterns are also changing, with the region experiencing an overall increase in precipitation (BC Ministry of Environment, 2016). The results of these many changes to the environment have far reaching ramifications for the citizens of VICC.

The VICC region is geographically and economically diverse. Approximately $40 \%$ of the population lives in Greater Victoria, $20 \%$ in medium-sized population centres and $40 \%$ in small urban population centers and rural areas (Krawchenko et al., 2020; see Appendix A for more details). Population areas (especially suburbs) in the southern VICC are growing while rural areas are shrinking. Due to their greater isolation, remote rural communities are more vulnerable to climate related hazards and are less equipped to respond in terms of administrative capacity and resources (Krawchenko et al., 2020). Rural communities also face high energy costs and have the highest per capita GHG emissions on average across the VICC (Krawchenko et al., 2020). Urban areas typically have more extensive mitigation and adaptation measures in place, but experience their own challenges, for example, greater development pressures, storm water management issues, and unique impacts such as urban heat islands (Simperler et al., 2020). They are also important service centres for surrounding areas. Cities are often located on or near the coast and have larger and denser populations, resulting in major impacts to people, properties, and infrastructure from climate change hazards like rising sea levels. With respect to climate change mitigation, urban centres are responsible for a large share of global energy consumption and GHG emissions, and therefore have a key role to play in transitioning to a sustainable future.

Many of the larger urban municipalities in the VICC have climate plans. For example, the City of Victoria's (2018) Climate Leadership Plan, the District of Saanich's (2020) Climate Plan: 100\% Renewable and Resilient Saanich, and the City of Nanaimo's (2012) Community Sustainability Action Plan, with mitigation policies focusing on buildings, transportation, land use, waste management, municipal operations, and energy systems. Canadian municipal climate plans tend to prioritize mitigation over adaptation (Guyadeen et al., 2018). For example, Nanaimo's 2012 Sustainability Action Plan focuses on energy and GHG emissions (i.e., mitigation only). However, more recent municipal plans in the VICC indicate growing attention towards adaptation planning: Saanich's 2020 climate plan integrates adaptation throughout, and Nanaimo has just produced an adaptation plan, the Climate Change Resilience Strategy (2020). The City of Campbell River has a community energy and emissions plan and climate adaptation planning is underway (City of Campbell River, 2020). Some smaller municipalities are also working on climate plans; for example, the District of Ucluelet developed its first climate action plan in 2019, and is working on a climate adaptation plan (District of Ucluelet, 2020). 
In these municipalities, mitigation targets are designed in alignment with established provincial and national commitments, as well as international climate targets. For example, Victoria committed in 2016 to reduce community-wide GHGs by 80 percent by 2050 from 2007 levels and to shift away from fossil fuels to 100 percent renewable energy by 2050 (City of Victoria, 2018). Nanaimo has set GHG emissions reduction targets of 33 percent below 2007 levels by 2020 and 80 percent below 2007 levels by 2050 (City of Nanaimo, 2012). Saanich has the most ambitious plan, with a goal to cut emissions in half by 2030 and net zero by 2050 , as well as to transition to 100 percent renewable energy by 2050 (District of Saanich, 2020).

Almost every local government in BC-187 of 190 municipalities, regional districts and the Islands Trust - has signed the BC Climate Action Charter. The Charter requires local governments to take action to reduce greenhouse gas emissions, report on community climate initiatives, and become carbon neutral in municipal operations. Despite this provincial commitment and the existence of a few climate plans and policies in larger urban centres, information on climate-related hazards, actions and priorities is not well-documented in the rest of VICC. The information gathered through our survey helps summarize all mitigation and adaptation policy information and the preferences and ambitions of local and regional governments in a consistent manner to help catalyse broader regional climate planning.

Regional planning is about responding to the development needs of interconnected places for which there is no corresponding level of government-i.e., between the locality and the province (Hodge, Hall, \& Robinson, 2016). As such, regional planning problematizes scale. The political and practical challenge of regional planning for the VICC region entails defining the region in a coherent way that makes sense for planning purposes. In some countries, this type of regional collaboration is defined in law-for example, France's Schéma Régional d'Aménagement et de Développement Durable du

CIP-ICU \& ACUPP-APUCU
Territoire (Desjardins \& Geppert, 2019). But for the VICC region, where no such institutional vehicles or collaboration incentives exist, there is a great deal of flexibility. It will be up to local actors to determine the structures that can best support common climate ambitions and objectives. The Canadian planning context tends to favour a degree of institutional informality in regional planning, as does climate planning. A comprehensive review of Canadian municipal climate change plans by Guyadeen et al. (2019) finds that they on the whole tend to prioritise mitigation over adaption; inadequately incorporate implementation, monitoring, and evaluation; and tend to not address public engagement in their processes. Thus, regional climate planning faces a number of barriers and, as with the case of the VICC region, the project is one of building political buy in and support for joint action. A common understanding of the region and community priorities is a first step.

\section{Methodology}

\subsection{Data collection}

Primary data about existing climate change hazards, climate action plans, policies, and priorities were collected using a web-based survey of local government officials $(\mathrm{n}=106)$ in each VICC community and regional district. Purposive sampling of respondents was employed using openaccess contact information of government officials from the CivicInfoBC (2020) directory and individual local government websites. Government officials included elected representatives as well as senior staff and administrators in municipalities and regional districts who are responsible for climate change mitigation and adaptation policies and actions. Multiple individuals from each local government were invited to participate in the survey, with the intention of aggregating the responses for a single municipality or regional district into one complete response. The survey instrument represents an initial scan of local government priorities to inform future steps in the VICC regional planning process, including First Nations engagement. For this reason, the survey was not distributed to First Nations communities. 
The survey invitation was sent by email to 384 government officials including 334 elected officials in 40 VICC municipalities and 10 regional districts. A total of 50 municipal and regional district chief administrative officers were also invited to participate and were asked to distribute the survey to relevant staff within their organization. Respondents were requested to complete the survey in their formal role as staff or representative of their local government and to refrain from offering personal opinions, though we acknowledge that some governments may not have a clear and uniform position on climate action, potentially resulting in some degree of personal bias in survey responses.

Responses were received from 38 municipalities and 10 regional districts (i.e., 95\% of all VICC municipalities and $100 \%$ of regional districts) making the study representative of local governments in the VICC region. Of the total 106 individual responses, 69 came from elected officials while 35 were from staff (two respondents declined to provide their role). All 10 regional districts provided full responses: 38 of 40 municipalities provided responses, and of these, 35 were complete while 3 were incomplete. An average amount of time to complete the survey was 23 minutes. Participation in the survey was completely voluntary with no incentives or compensation offered in exchange for completing the survey. The survey was designed and administered using University of Victoria's SurveyMonkey platform.

The survey consisted of four key sections related to (1) general information about the community, (2) climate change mitigation, (3) climate change adaptation, and (4) hazards and impacts (see Appendix B for a full survey questionnaire). This survey design was informed primarily by municipal climate change action survey guidelines by Fisher (2011). Sections on mitigation and adaptation policy options also drew on the Government of British Columbia's (2012) climate policy implementation guide for local governments, the Federation of Canadian Municipalities' (2009) summary of municipal mitigation policies, as well as existing municipal and regional climate action plans including the City of Victoria's (2018) Climate Leadership Plan, the City of Nanaimo's (2012) Community Sustainability Action Plan, the Capital Regional District's (2017) Regional Climate Action Strategy, the Regional District of Nanaimo (2013) Community Energy and Emissions Plan, and the City of Barrie (2017) Climate Change Adaptation Strategy.

Each survey section included a mix of open-ended and closed-ended questions. Because of the study's exploratory nature, the questions were not designed to test a specific conceptual framework. Rather, the questions gathered consistent information on current and future local government priorities to support the development of a regional climate plan. The survey questions were pre-tested by researchers in the University of Victoria and VICC-CLP representatives.

In the first section, respondents were asked general questions about their local government, including government motivations to act on climate change using a mix of open-ended and closed-ended multiple choice and Likert-type scale questions. In the following section on climate change mitigation, respondents were asked mostly closed-ended questions about general support, top priorities, main policies, and barriers for reducing climate change. The policy list was based on the Federation of Canadian Municipalities' (2009) summary of municipal mitigation policies, as well as a review of policy options from local government climate plans. The section on climate change adaptation employed a similar set of questions as in the preceding mitigation section but with the list of policy options tailored toward adaptation and derived from a review of government documents including the provincial government's implementation guide for preparing for climate change (Government of British Columbia, 2012) and the City of Barrie's (2017) adaptation strategy. In the final section on hazards and impacts, open-ended and closed-ended (i.e., multiple choice and matrix style Likert-type scale) questions were asked about past and future hazards based on Fisher (2011). Definitions of the 
terms "hazard" and "impact" were provided to respondents based on Oppenheimer et al. (2014). Some of the last survey questions focused on the new opportunities related to the changing climate as well as the impact of the COVID-19 crisis on mitigation and adaptation efforts.

\subsection{Data analysis}

Of the total 48 local governments that responded to the survey, 21 had one respondent, while 19 municipalities and 8 regional districts had more than one respondent. Responses from communities with more than one respondent were merged together to form one complete response per municipality or regional district using the following methods: (1) responses were combined to fill in blank sections of survey (i.e., in some cases, respondents from one community divided sections of the survey among themselves); (2) where two or more respondents filled in the same sections of the survey, procedures were developed to merge the responses. These procedures included using an averaging/majority rules strategy where the most frequent response was chosen, and grouping of response options (e.g., "important" and "somewhat important" were combined into one category; "supportive" and "somewhat supportive" were combined into one category). For answers with an "I don't know" option, any alternative response would replace "I don't know" (e.g., where to find information). New categories of "limited preparedness/capacity/ frequency" were developed where disagreements could not be resolved using the above rules. We acknowledge that some of the aforementioned data analysis procedures might have overlooked nuanced responses and/or resulted in homogenization of responses within each local government. However, such procedures were necessary to address the study's objective to identify the main climate impacts, barriers, and opportunities for climate action in the region.

Respondents were followed up with by email to confirm information in cases where variation between answers from a single jurisdiction could not be otherwise resolved. In total, 10 local governments (two regional districts and eight municipalities) were followed up with via email. The questions requiring follow up included: strategic climate plan (9), dedicated climate staff (3), Indigenous knowledge (3), climate adaptation importance (1), and overall support for climate adaptation (1).

Municipalities were categorized into four subregions--North Island, Central Island, South Island, and Coast, in order to examine the effects of geography on climate action as well as hazards and impacts experienced. Municipalities were also categorized by population size in order to examine how differently sized municipalities experience and respond to climate impacts. The population size categorization was based on the one developed by the Union of BC Municipalities (2020), where municipalities with populations less than 5,000 are considered small, 5,000-20,000 mid-sized, and greater than 20,000 large (see Appendix A).

Descriptive statistics were used to analyze data, including calculation of frequencies for multiple choice questions. There were three municipalities that only filled in a small section of the survey and others that skipped certain questions. In calculating frequencies, municipalities that did not answer a question/section of the survey were excluded from the total. Contingency tables, using the pivot table function in MS Excel, were used to compare multiple variables, as in the analysis of the effect of geography and municipal size on hazards/impacts experienced and policy options implemented. We report on the number of mitigation and adaptation policies throughout the paper to emphasize administrative capacity differences across different sizes and geographies of VICC communities - the number of policies does not translate into their effectiveness in addressing climate change mitigation or adaptation. Open-ended questions were analyzed to identify common response themes using manual scanning of responses given the small sample size. We used these themes to support and/ or explain findings from multiple choice questions. 
A case for regional climate planning in the Vancouver Island and Coastal Communities region

\section{ReSUlts}

\subsection{Motivations to act on climate change}

Both municipalities and regional districts are overwhelmingly supportive of climate action: 100\% of municipalities and regional districts answered that climate change mitigation and adaptation are "important" or "somewhat important" to their community. Only one municipality answered that their community is not supportive of implementing mitigation or adaptation policies.

An analysis of open-ended responses found that the top five common themes of motivation to act include: (1) public and/or political demand; (2) science and data on climate change including observable impacts from changing weather patterns such as increased storms, droughts, and wildfires; (3) concern about sea level rise; (4) preparation for the future and concern for future generations; and (5) support and funding from senior levels of government. Several municipalities referenced their declarations of climate emergency and mentioned emissions reductions targets and/or climate action committees that have been established. Regional districts were particularly likely to mention senior government funding and support as an enabling factor in being motivated and able to take action. The survey results showed that on the whole, municipalities and regional districts in the VICC region are well aware of the issues related to climate change, are already observing the effects, and are motivated to take action:

"We are motivated and have declared a climate crisis, have written to oil companies and, most significantly, are re-writing our Official Community Plan with a climate change lens." - Courtenay.

"Council members are strongly and personally motivated. For some councillors, it is their prime motivation for being in local politics." - Highlands.

"[We are motivated by] public pressure, escalating costs for infrastructure repairl replacement, but mostly having senior government enable us (and fund us) to take action." - Sunshine Coast Regional District.

"[We are motivated by] sea level rise, obvious changes to our weather patterns, specific environmental issues as they arise." Strathcona Regional District.

"Climate change is a public and therefore political priority. CRD and Islands Trust emergency declaration is spurring action. Climate change impacts such as forest fires and drought are already being felt here." Islands Trust.

\subsection{Climate change-related hazards and impacts}

Virtually all municipalities and regional districts are already experiencing hazards and impacts related to changing weather patterns caused by climate change. The unique island and coastal geography of the region influences the types of hazards and impacts that are experienced in this area compared to other regions of the province. The distinct challenges related to island and coastal communities were reflected in open-ended comments:

"We experience multiple power outages in any given year and often have road/access issues due to wind/rain storms on a yearly basis. We had a wildfire above the town 2 years ago. We live in a deep valley, surrounded by forest, on a flood plain in an earthquake and tsunami zone." - Zeballos.

"Saanich is positioned in a climate that is naturally challenging such as being located within a rainshadow and a rare ecosystem. This has caused many streams to dry up during the summer and loss of biodiversity. Climate change is adding to these stressors by further reducing environmental flows, stressing remnant ecosystems, and impacts from poor air quality from wildfires." - Saanich.

"Small islands have a more obvious finite land base and natural resources and any

Aménagement et politique au Canada 2021 
climate impacts will have a greater impact to our communities." - Islands Trust.

All except for one municipality indicated that they have experienced hazards related to climate change with wildfires, extreme rainfall, sea level rise, storm surges, extreme winds, and droughts being the key hazards (Figure 2). Municipalities and regional districts identified additional hazards other than those listed in multiple choice responses including tsunamis, earthquakes, heating tank oil spills, air quality, and pandemics. Tsunamis and earthquakes were the most frequently mentioned "other" hazards.

There are some geographic differences and commonalities in the hazards experienced in the different sub-regions. Wildfire is the top hazard overall for both municipalities and regional districts, and is a top three hazard in all areas (i.e., North Island, Central Island, South Island, and
Coast). Extreme rainfall is one of the top three hazards for island municipalities but is not in the top three for coastal municipalities. Sea level rise and drought are top concerns in the Southern region of Vancouver Island and the Coast region but less of a concern in the Central and Northern parts of Vancouver Island. Reduced snowpack was less of an issue in Northern municipalities compared to other areas; conversely, landslides are a top concern in Northern municipalities but not a high concern in other areas.

In the North Island, the top hazards indicated by municipalities included wildfires (89\%), extreme rainfall (78\%), landslides (78\%), storm surges, flooding, and extreme wind (56\% each). Central Island top hazards included wildfire $(82 \%)$, extreme rainfall $(73 \%)$, reduced snowpack $(73 \%)$, drought (64\%), and sea level rise (64\%). In the South Island, top hazards included sea level rise $(83 \%)$, extreme rainfall (75\%), wildfires, extreme wind, and drought

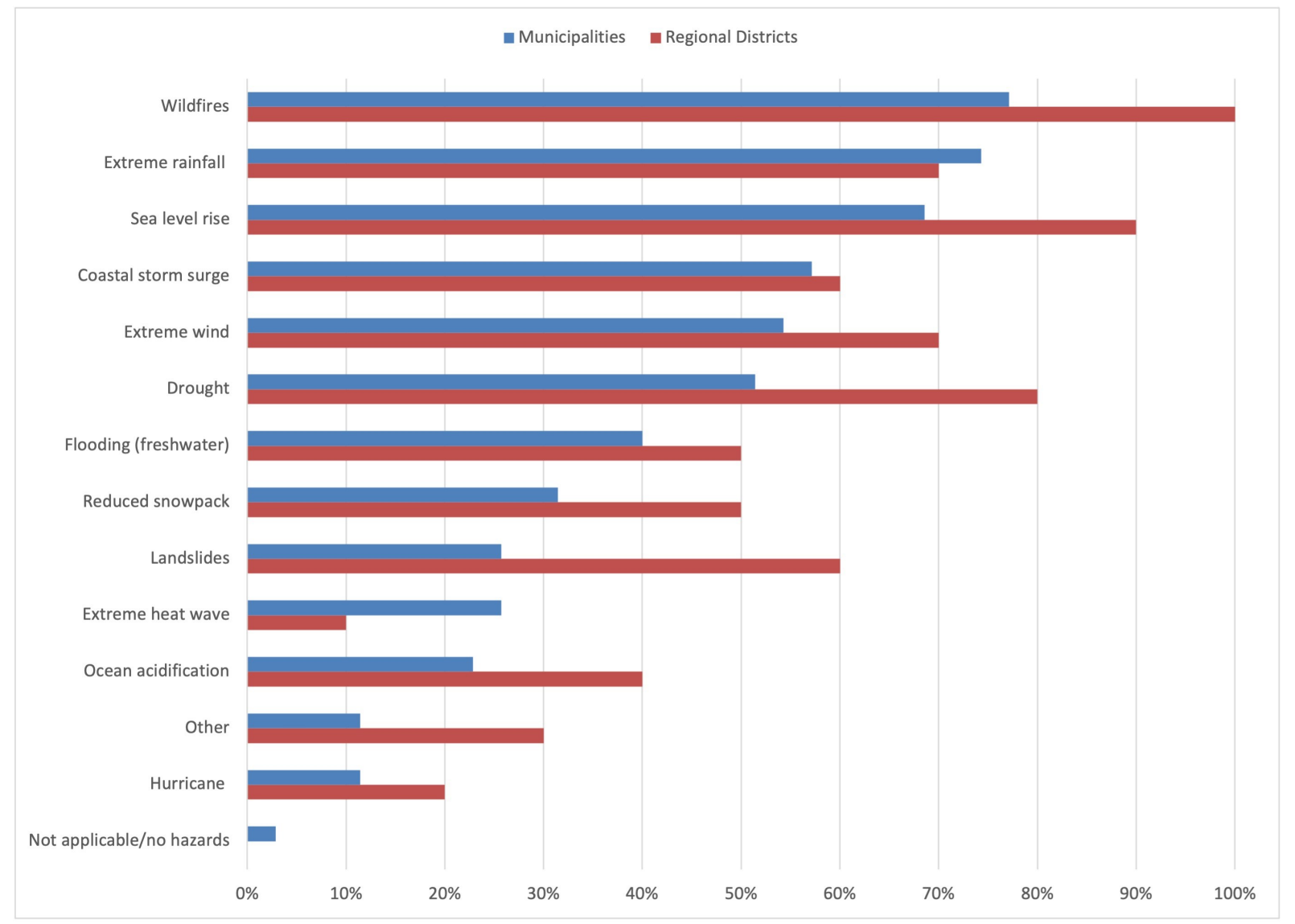

Figure 2. Hazards experienced in municipalities and regional districts. 
(58\% each). Finally, in the Coast sub-region, the top hazards were wildfires, storm surges, sea level rise, and drought (100\% each).

Hazards also varied by the size of municipality (Figure 3). The top hazards for small municipalities $(<5,000$ people) included wildfires $(80 \%)$, extreme rainfall $(73 \%)$, and extreme wind $(60 \%)$. Medium municipalities $(5,000-20,000$ people) indicated top hazards such as sea level rise (86\%), wildfires $(71 \%)$, and extreme rainfall $(64 \%)$. The top hazards for large municipalities (>20,000 people) were extreme rainfall $(100 \%)$, wildfires $(83 \%)$, and coastal storm surge $(83 \%)$.

Wildfire and extreme rainfall were top hazards in municipalities of all sizes. Larger municipalities were more likely to prioritize hazards, with a number of hazards being indicated as more prevalent in large municipalities compared to small and medium-sized municipalities. Although heat waves were not a top hazard overall, they were identified as more of a problem in urban areas, and are a top concern in two out of three of the largest urban municipalities. Landslides stood out as being more a concern for small municipalities as compared to medium and large municipalities, which may relate to the remote nature of many of the smallest municipalities.

In terms of being prepared for most top hazards identified, most municipalities indicated they are fairly well prepared and have either strong or some capacity to handle the next hazard. Although wildfires are the most frequent hazard, almost all municipalities (93\%) that identified wildfire as a top hazard are "prepared" or "somewhat prepared" to handle the next event. Sea level rise and ocean acidification are the hazards municipalities feel least prepared to handle (of those who identified sea

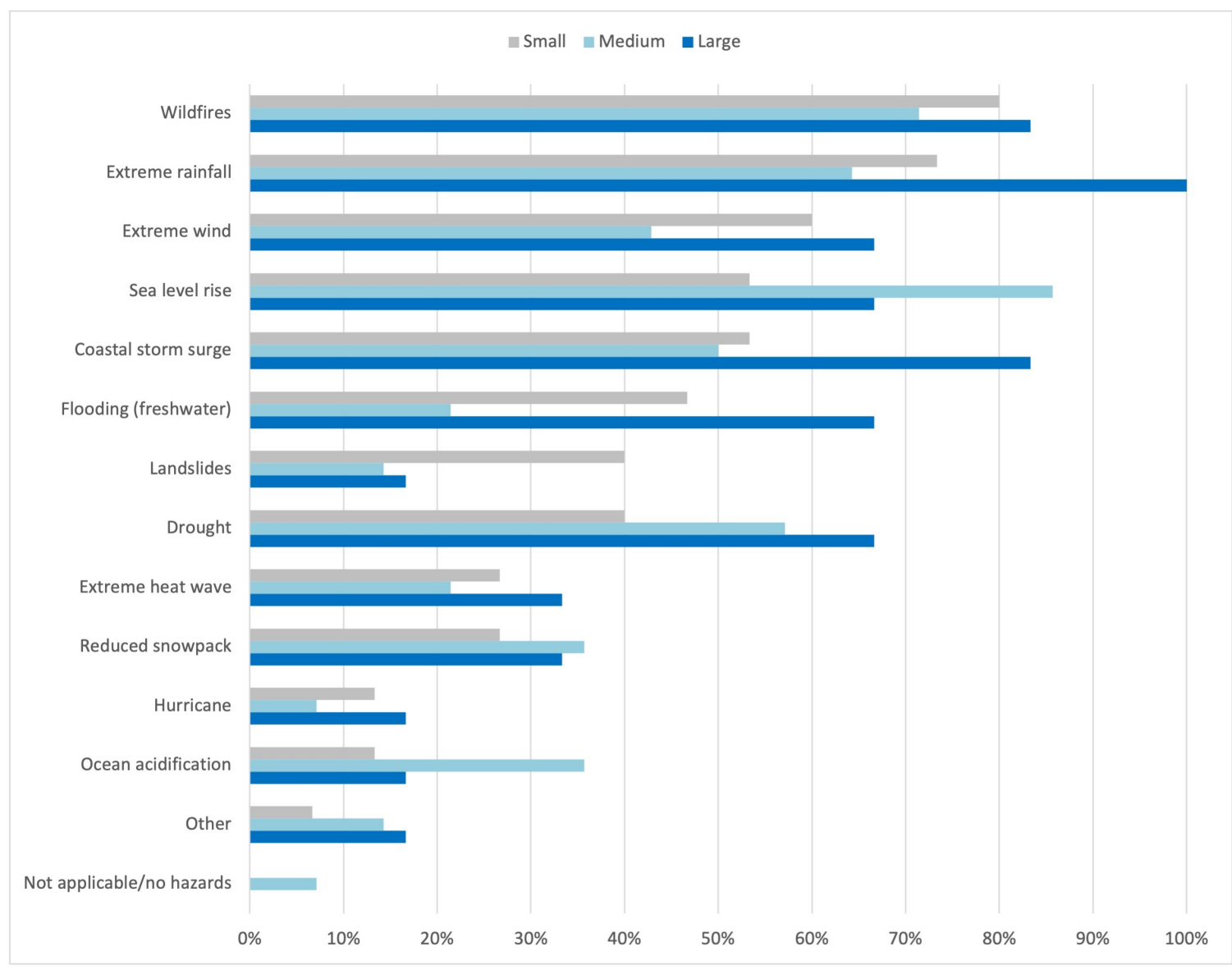

Figure 3. Comparison of climate change hazards by size of municipality. 
level rise as a top hazard, only $42 \%$ are "prepared/ somewhat prepared;" of those who identified acidification as a top hazard, all have "limited or no preparedness").

After identifying hazards, respondents selected top impacts of those hazards. The top impact identified by both municipalities (49\%) and regional districts $(100 \%)$ was impacts to coastal ecosystems. After coastal ecosystems, the most frequently identified impacts for municipalities included aquatic resources and fisheries $(46 \%)$, food security $(46 \%)$, forests and forestry (43\%), and land-based ecosystems $(40 \%)$. The next most frequently identified impacts for regional districts included aquatic resources and fisheries $(90 \%)$, biodiversity $(90 \%)$, water supply issues $(90 \%)$, and land-based ecosystems (80\%) (Figure 4).
There are distinct regional differences in the impacts experienced. In the North Island, the top impacts indicated by municipalities were to tourism/ recreation (67\%), forests/forestry (67\%), and electricity supply $(56 \%)$. In this sub-region there were no air quality, public health impacts, or water supply issues identified. Municipalities in the Central Island indicated poor air quality (55\%), demand on emergency services, aquatic resources/ fisheries, and water supply issues (45\% each) as top impacts. In the South Island, the top impacts included land-based ecosystems (67\%), coastal ecosystems $(67 \%)$, and poor air quality $(50 \%)$. The top impacts in the coastal sub-region included pests/ invasive species and food security (100\% each), and land based and coastal ecosystems (67\%). No public health impacts or water quality impacts were indicated in the Coast area.

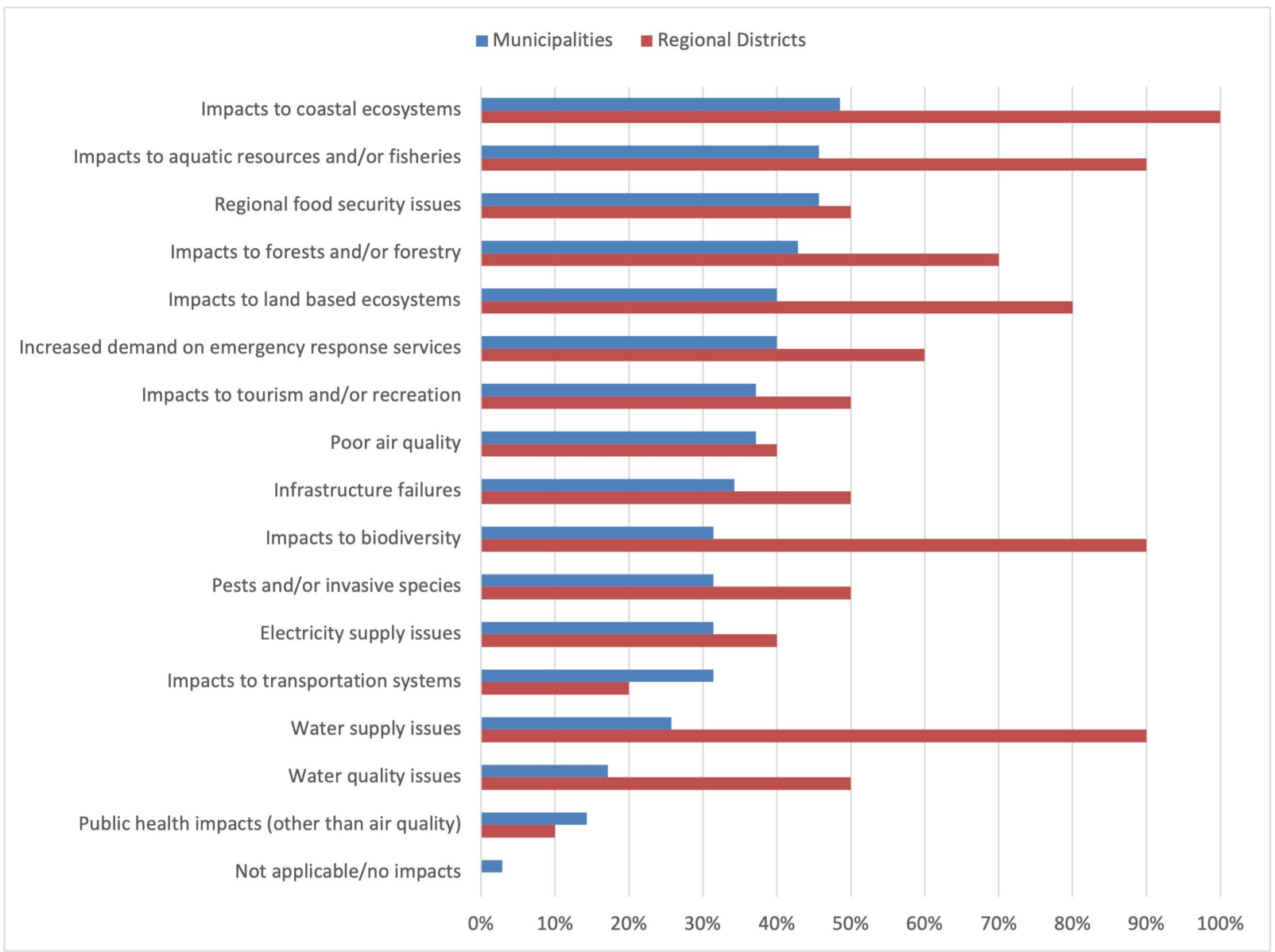

Figure 4. Climate change impacts experienced in municipalities and regional districts. 
Climate change impacts also varied by municipality size (Figure 5). In small municipalities $(<5,000$ people) the top impacts were to forests/forestry $(53 \%)$ and demand on emergency response services (47\%). The top impacts in mid-sized municipalities (5,000-20,000 people) included impacts to coastal ecosystems $(57 \%)$, poor air quality, and pests and/or invasive species (50\% each). In large municipalities $(>20,000$ people), the top impacts were poor air quality $(67 \%)$, impacts to aquatic resources and/or fisheries $(67 \%)$, impacts to coastal and land based ecosystems, food security, and biodiversity $(50 \%$ each).

Small municipalities were more likely than midsized and large municipalities to identify impacts to forestry, emergency response resources, electricity supply, tourism/recreation, and water quality. The impacts that are important to small communities reflect to some extent the closer linkage and dependency on natural resources, especially the importance of forestry. The demand on emergency response services may be a bigger problem for these small municipalities due to their smaller administrative capacity and the remoteness of many small communities.

Medium and large municipalities were more likely to identify impacts to aquatic resources, coastal ecosystems, and land-based ecosystems as a top impact compared to small municipalities. Large municipalities were the most likely to identify impacts to biodiversity as a key impact compared to smaller municipalities. Air quality and health impacts were the least frequently chosen for small municipalities, but medium and large municipalities are much more affected by poor air quality compared to small municipalities, and large municipalities are more affected by other types of public health impacts as compared to small and medium sized municipalities. These differences are even more pronounced when examining only the largest urban municipalities, all three of which indicated poor air quality as a top impact and two out of three indicated other public health impacts.

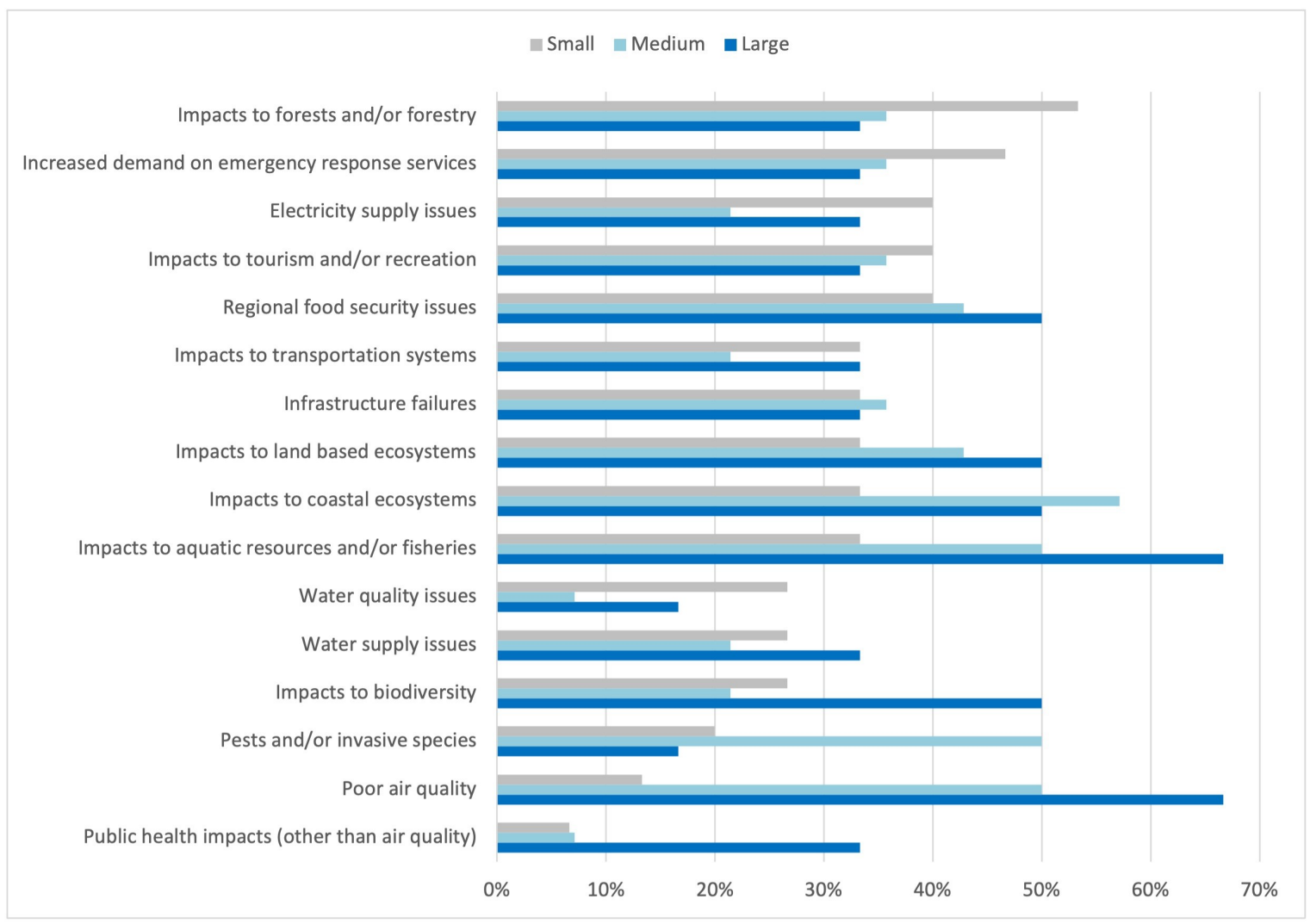

Figure 5. Comparison of climate change impacts by size of municipality. 
A number of respondents pointed to the interrelated and cumulative nature of hazards and impacts in open-ended comments. Most communities expect these hazards and impacts to increase into the future. The majority of municipalities believe that the climate change related impacts they identified will continue and/or worsen, ranging from $67 \%$ for water quality issues to $93 \%$ for food security and impacts to land-based ecosystems. The majority of regional districts believe impacts to the community identified in the survey would become more problematic in the future for all impacts except for electricity supply. For all other impacts, the percentage that believe impacts will get worse ranged from $60 \%$ to $100 \%$.

Survey respondents were also asked how and why they expected climate impacts to become more of a problem over time (Figure 6). The most frequent response for both municipalities and regional districts was increased frequency and/or intensity of hazardous events $(71 \%$ municipalities; $100 \%$ regional districts), and lack of capacity to respond to multiple or cumulative events (71\% municipalities; $100 \%$ regional districts). Municipalities also identified system failures due to aging infrastructure (71\%) and changing demographics (69\%) as key areas of vulnerability. Regional districts identified changing demographics, housing issues, vulnerable populations, and increased geographic area exposed to hazards (90\% each) as key vulnerabilities.

Nearly half of municipalities (46\%) believe their community will experience new impacts in the future, and another $51 \%$ think they might experience new impacts. Most regional districts $(80 \%)$ believe they will experience new impacts which have not affected them in the past. Some of the future impacts described by respondents include flooding, sea level rise, increased pests and invasive species, impacts to food and water security, more frequent extreme weather events, increased human disease, impacts to forests including specific tree species such as cedars, damage to ecosystems, migration of climate refugees, and loss of Indigenous food and medicines. The quotes below

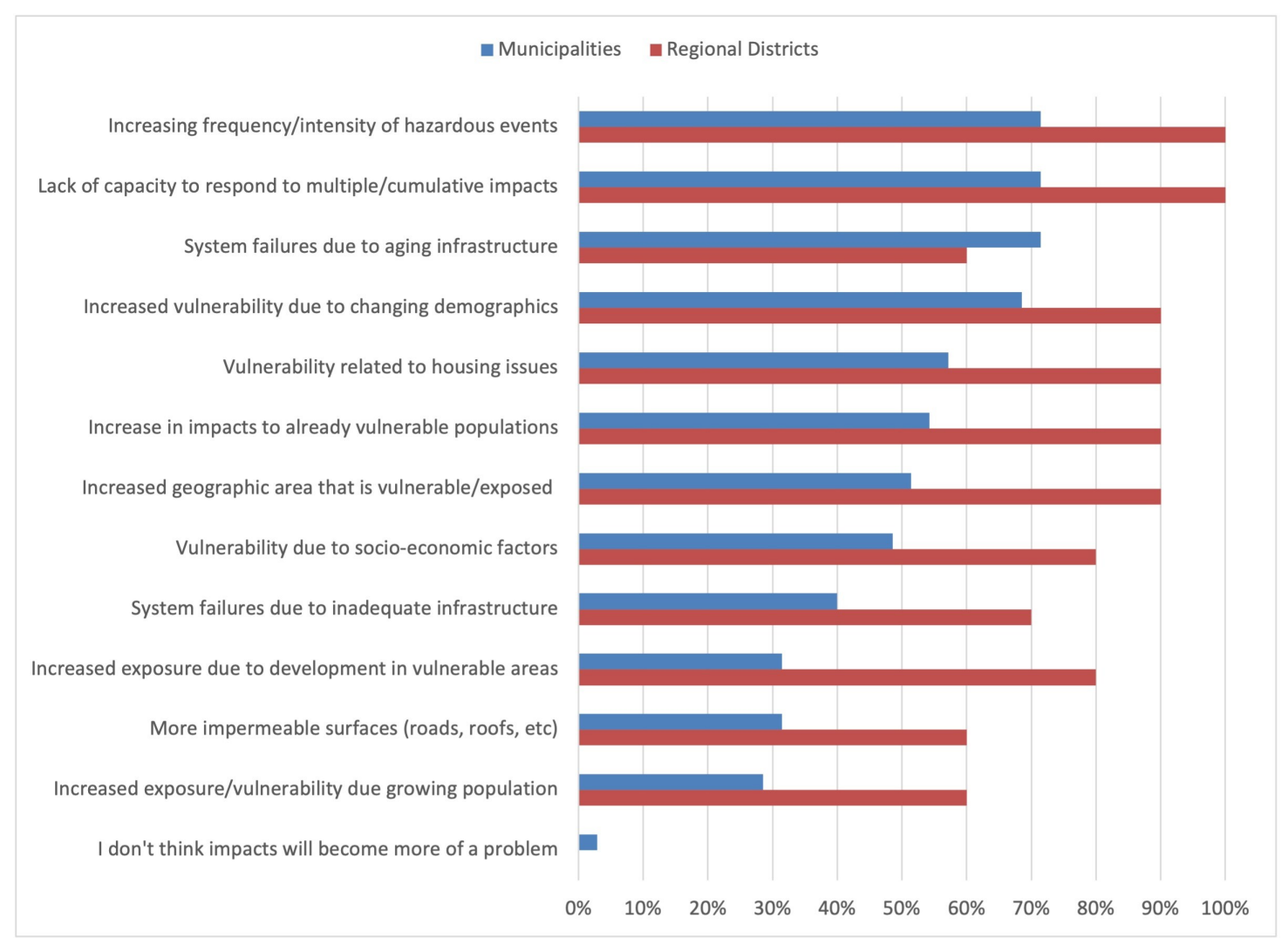

Figure 6. Reasons for increased vulnerability to climate impacts. 
A case for regional climate planning in the Vancouver Island and Coastal Communities region

speak to the anticipated future impacts of climate change:

"The way climate impacts combine or accumulate means there are many impacts we can't anticipate but will likely deal with...As our landscapes change and we lose biodiversity, we can't predict the cascading impacts that will have on other living systems. Climate migrants and local food shortages are potential impacts we could deal with in the future. Climate change may impact trends in tourism, interface fire risks, etc." Victoria.

"Sea level rise has not affected us to date, but this is changing. Likelihood of pests/invasive species appearing not previously seen. Wildfire and air quality, invasive plants and animals including noxious pests, human disease, climate refuges, ecosystem collapse, food insecurity, social breakdown." Campbell River.
"While water quality and quantity don't seem to be an issue yet...our study indicates that ground water resources are expected to be affected by climate change." - Highlands.

"Once very rare emergency events (extreme weather, storm surges, drought, floods, wildfires) are now becoming regular although still manageable events." - Mount Waddington Regional District.

"Many of the likely impacts have not been functionally realized on the islands but it is inevitable that they will including wildfires, loss of bio-diversity, sea level rise and increase in storms. " - Islands Trust.

Survey respondents listed the top five types of information needed to plan for the future with respects to the hazards and impacts identified in the survey (Figure 7). Municipalities identified localized climate modelling and projected scenarios (69\%), risk assessment of hazards (69\%),

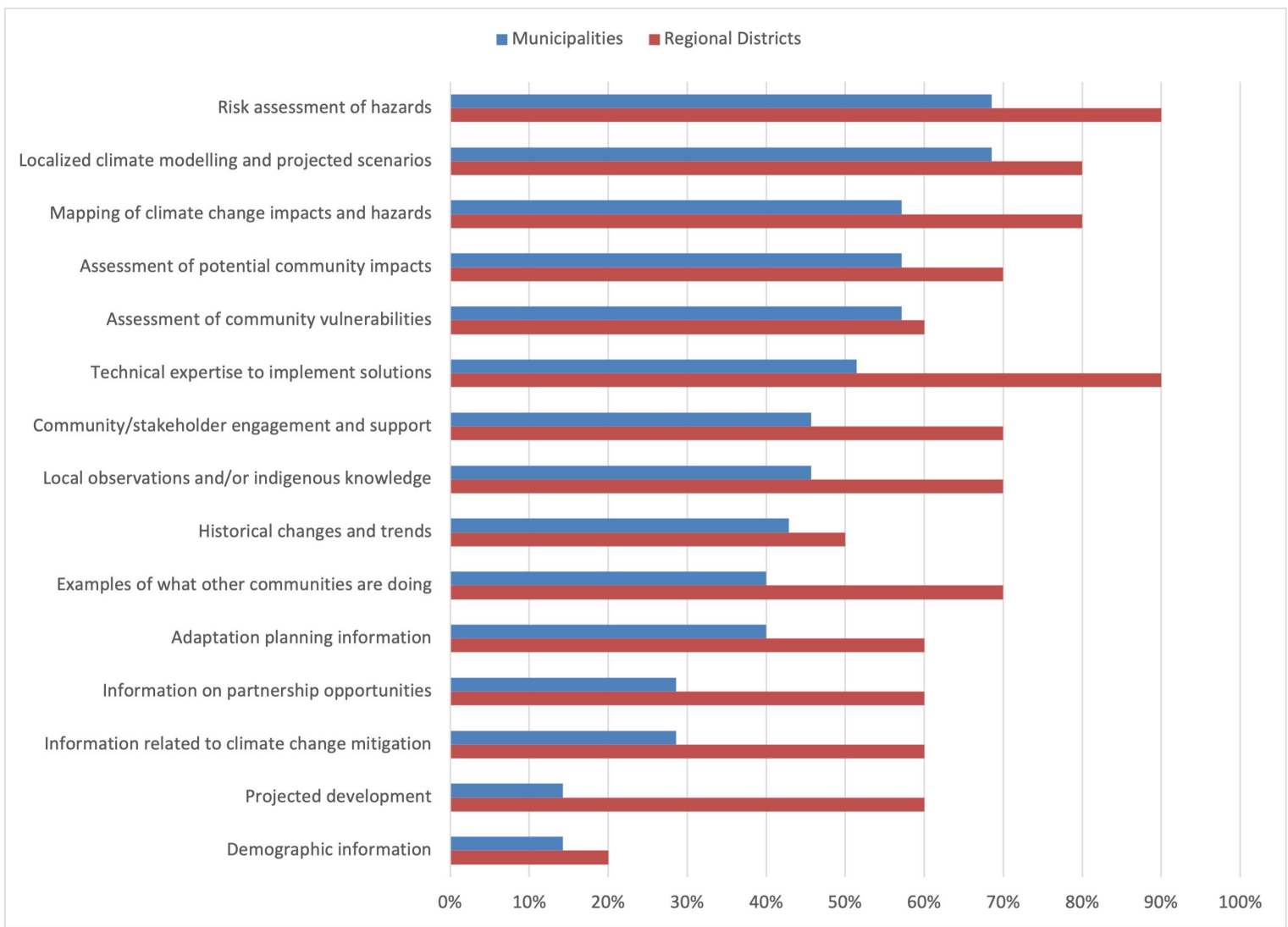

Figure 7. Information needed to plan for the future. 
assessment of potential community impacts $(57 \%)$, assessment of community vulnerabilities (57\%), and mapping of climate change impacts and hazards $(57 \%)$ as the most important information needed.

Regional districts tended to identify more information needs than municipalities. The types of information identified by regional districts included risk assessment of hazards $(90 \%)$, technical expertise $(90 \%)$, localized climate modelling and projected scenarios $(80 \%)$, mapping of climate change impacts and hazards (80\%), local observations and/or Indigenous knowledge (70\%), assessment of potential community impacts $(70 \%)$, community engagement $(70 \%)$, and examples of what other communities are doing $(70 \%)$.

\subsection{Climate change mitigation}

Municipalities and regional districts are overall highly supportive of taking action to mitigate climate change, and almost all have mitigation policies in place. Some of the most frequently mentioned future priorities for climate change mitigation include land use planning, public transit, pedestrian and cycling infrastructure, building standards, fleet management, and tree and forest conservation.

Municipalities and regional districts have implemented mitigation policies across a range of sectors, including government operations, buildings, transportation, land use, and solid waste management. Policies exist in almost all municipalities (Figure 8); only two indicated they have no mitigation policies currently in place. Most policies are investment-like policies, followed by regulations and incentives. The most frequently selected policy options included GHG mitigation in buildings and fleet (75\%), pedestrian/cycling infrastructure $(75 \%)$, and policies to increase

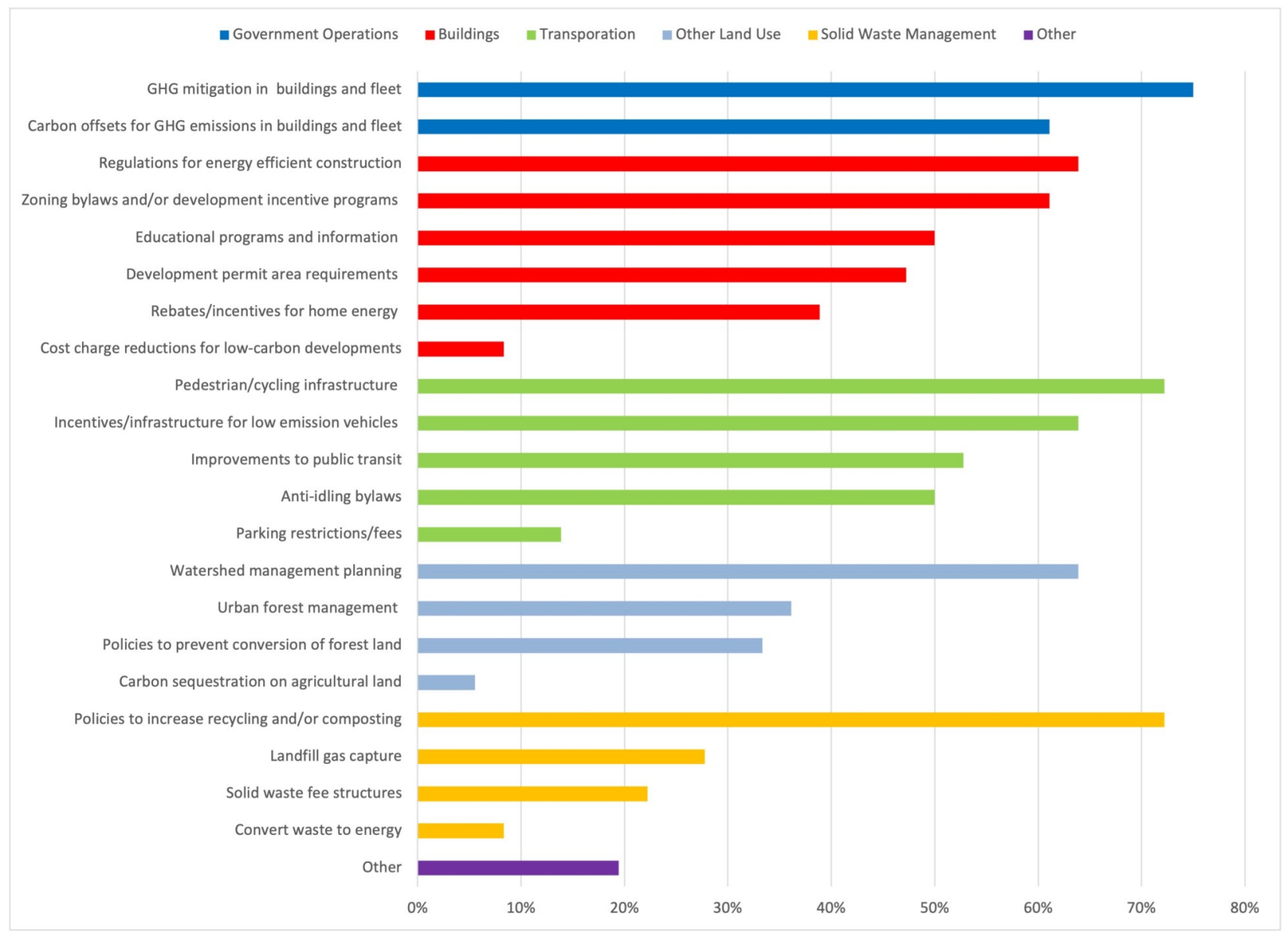

Figure 8. Municipal mitigation policies by sector. 


\section{A case for regional climate planning in the Vancouver Island and Coastal Communities region}

recycling and/or composting (72\%). Respondents were given the choice to indicate other policies not included in the list of options. These policies included asset management, flood/sea level rise impact and mitigation studies, use of bio-diesel or renewable natural gas, investments in urban forest/ tree planting, and public education.

Climate change mitigation policies exist in all regional districts, across all sectors (Figure 9). Regional districts tend to have a higher number of policies in place compared to municipalities (average of 13 versus 9 for municipalities). The most frequently implemented policies in regional districts included improvements to public transit $(100 \%)$, watershed management planning $(90 \%)$, and policies to increase recycling and/or composting $(90 \%)$. Differences in jurisdiction explain some of the differences in policies between regional districts as compared to municipalities; for example, regional districts tend to have more policies in the area of solid waste management. "Other" policies indicated by regional districts included water conservation measures, heat recovery, biosolids/ woodwaste composting, integration of mitigation into plans including Official Community Plans (OCPs) and regional growth strategies, urban containment boundaries, and protection of Douglas fir.

Municipalities in the North Island sub-region tend to have the fewest climate change mitigation policies in place, with an average of five policies per municipality. The average is even lower when assessing by municipality size, with an average of only three policies per small municipality $(<5,000$ people). Interestingly, the sole large municipality in the northern area, Campbell River, had the highest number of policies of any municipality with 18 policies. The most frequent policies in northern

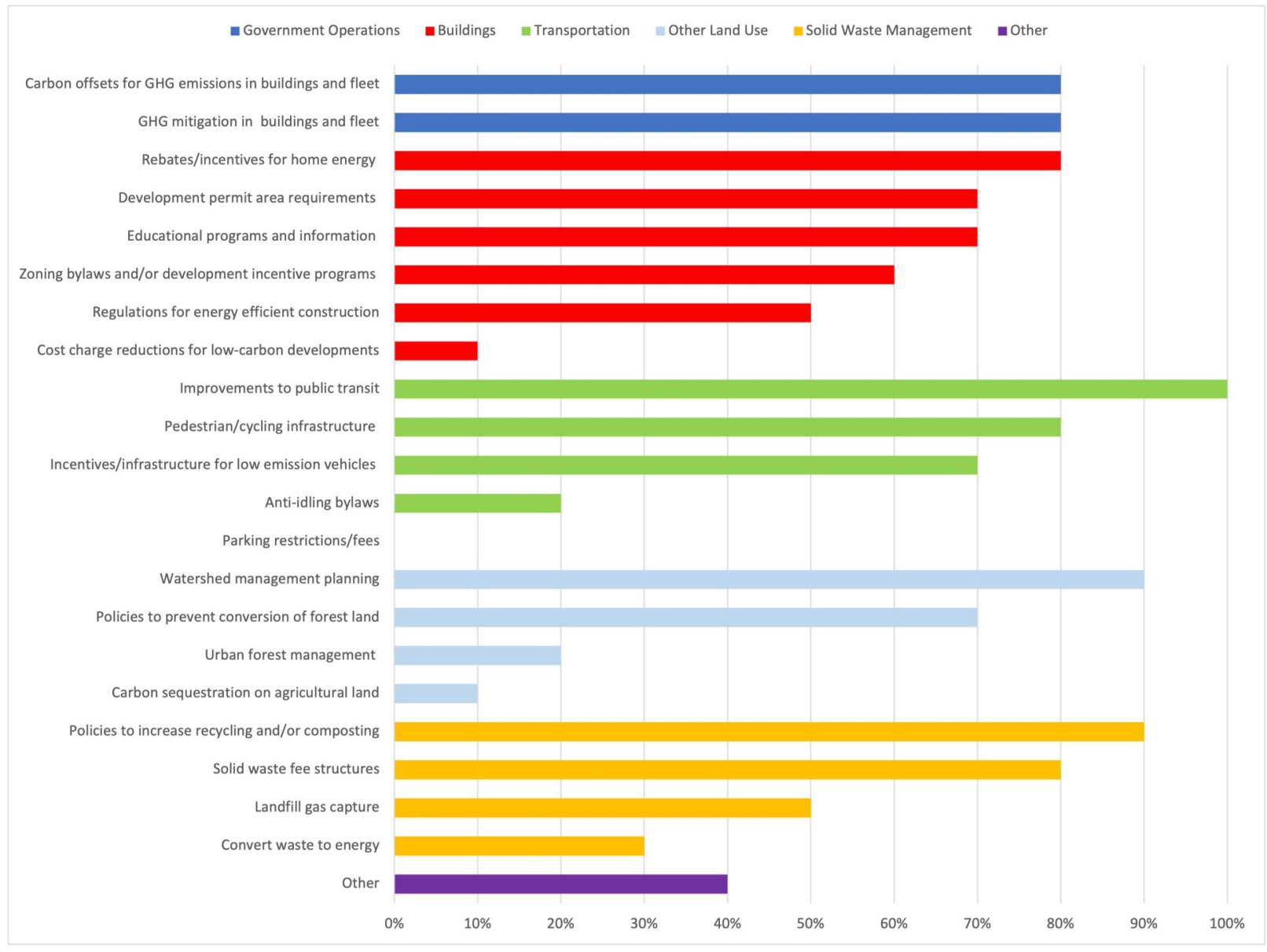

Figure 9. Regional districts' mitigation policies by sector. 


\section{A case for regional climate planning in the Vancouver Island and Coastal Communities region}

municipalities included recycling/composting, watershed management, and GHG mitigation in civic buildings and fleet ( $44 \%$ each). In the Central Island, municipalities had an average of ten mitigation policies each. The most frequent policies included recycling/composting and GHG mitigation in buildings and fleet $(83 \%$ each), followed by watershed management, pedestrian/cycling infrastructure, incentives/infrastructure for low emissions vehicles (LEVs), zoning bylaws/ development incentives, and carbon offsets $(75 \%$ each). In the South Island, there was an average of 12 policies per municipality. The top policies included regulations for energy efficient new construction $\quad(100 \%), \quad$ pedestrian/cycling infrastructure (92\%), educational programs/ information (83\%), GHG mitigation in civic buildings and fleet (83\%), recycling/composting (75\%), incentives/infrastructure for LEVs $(75 \%)$, and zoning bylaws/development incentives (75\%). The Coast also had an average of 12 policies per municipality. The most frequent policies implemented in coastal municipalities include recycling/composting, infrastructure, zoning bylaws/development incentives, development permit area requirements, GHG mitigation in buildings and fleet, and carbon offsets (100\% each).

Climate change mitigation policies vary by municipality size (Figure 10). In small municipalities $(<5,000$ people), the most frequently

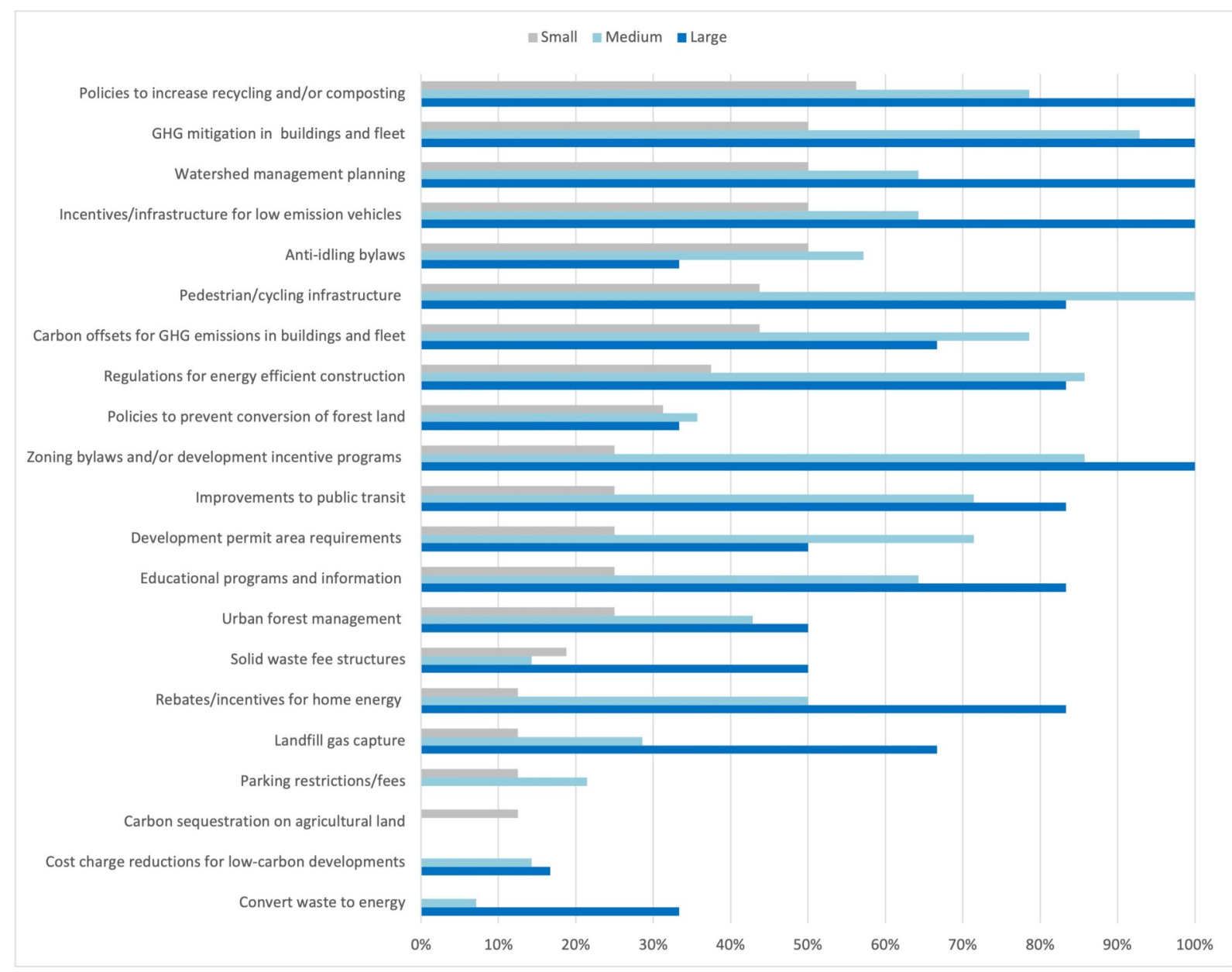

Figure 10. Mitigation policies by municipality size.

\footnotetext{
${ }^{1}$ See for example the comprehensive Indicators of Climate Change for British Columbia by BC's Ministry of the Environment (2016) and research by Denman and Macdonald (2017) on increasing ocean temperatures and acidification.
} 


\section{A case for regional climate planning in the Vancouver Island and Coastal Communities region}

implemented policies included recycling/ composting (56\%), GHG mitigation in buildings and fleet $(50 \%)$, watershed management planning (50\%), incentives/infrastructure for LEVs $(50 \%)$, and anti-idling bylaws (50\%). In mid-sized municipalities $(5,000-20,000$ people), the top policies included pedestrian/cycling infrastructure $(100 \%)$, GHG mitigation in buildings and fleet (93\%), zoning bylaws and/or development incentive programs $(86 \%)$, and regulations for energy efficient construction $(86 \%)$. In large municipalities $(>20,000$ people), the most frequent policies included recycling/composting, GHG mitigation in buildings and fleet, watershed management planning, incentives/infrastructure for LEVs, and zoning bylaws/development incentive programs $(100 \%$ each). The total number of mitigation policies implemented corresponds roughly to municipality size, with small municipalities having an average of six policies, mid-sized municipalities having an average of 11 policies, and large municipalities an average of 13 policies. The smallest, remote municipalities in the north have the fewest policies (only three policies per small northern municipality on average), while the three largest urban municipalities average 15 policies each.

When asked about community support for different policy types, respondents indicated the highest level of support for investments in pedestrian and cycling infrastructure (Figure 11). The most supported policies in municipalities included pedestrian and cycling infrastructure (69\%), GHG mitigation in civic buildings and fleet $(69 \%)$, and improvements to public transit $(67 \%)$. In regional districts, the policies with the highest support included pedestrian and cycling infrastructure, rebates/incentives for home energy upgrades, and watershed management planning (100\% each). Government investment and

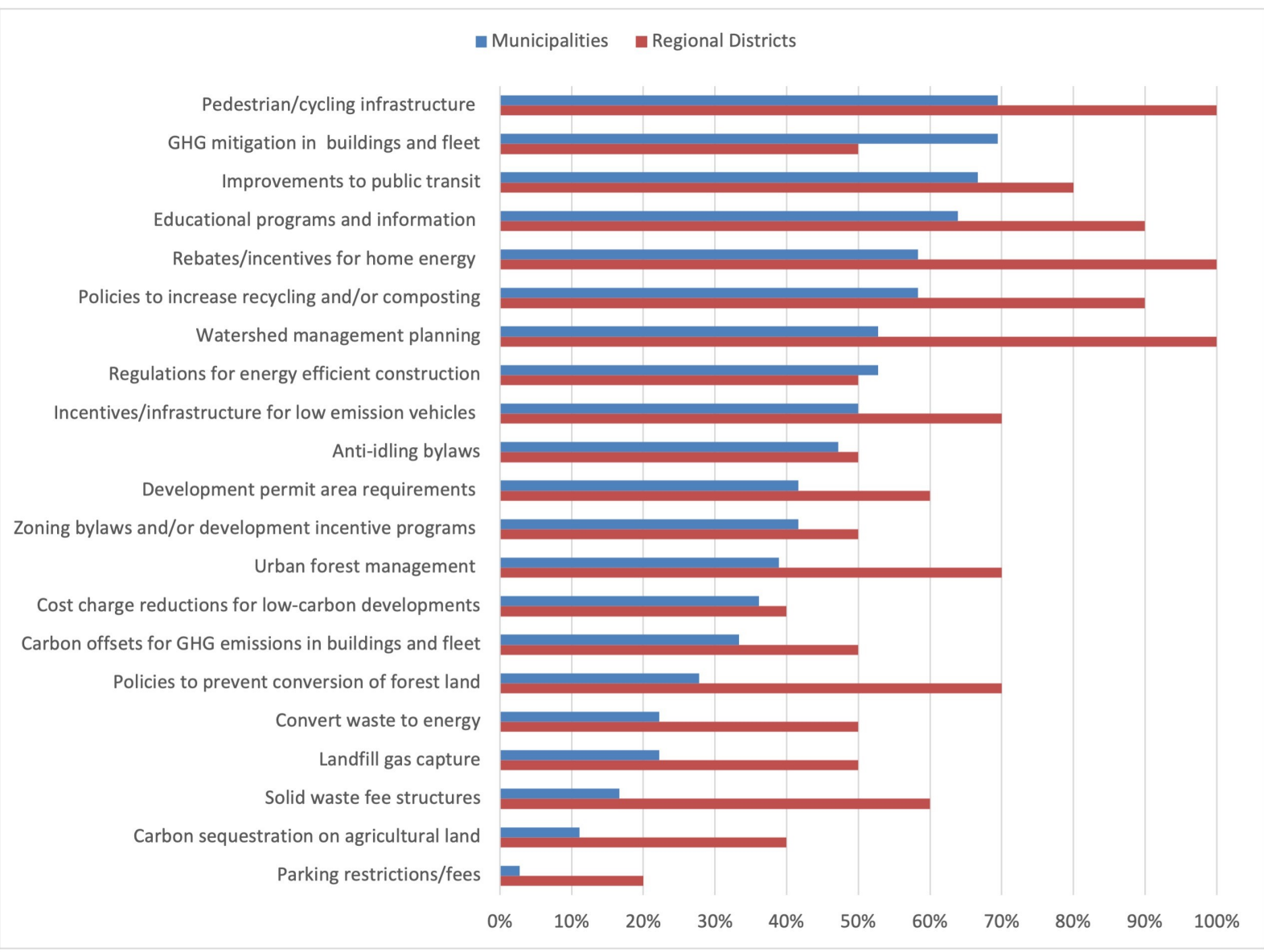

Figure 11. Support for climate change mitigation policies. 
incentives, as well as voluntary actions, tend to receive higher support than regulations and pricing. Although most municipalities and regional districts indicated support for climate action, one respondent noted concerns about costs of climate change mitigation:

"Support is sometimes a hard sell, even if it is cost effective because there is a general belief that climate policies have higher costs than need be." - Regional District of Mount Waddington.

Despite high support for climate action, local governments face a number of barriers to climate action. In both municipalities and regional districts, lack of financial resources ( $92 \%$ of municipalities, $100 \%$ of regional districts) and lack of staff capacity ( $83 \%$ of municipalities, $100 \%$ of regional districts) are the top barriers (Figure 12).

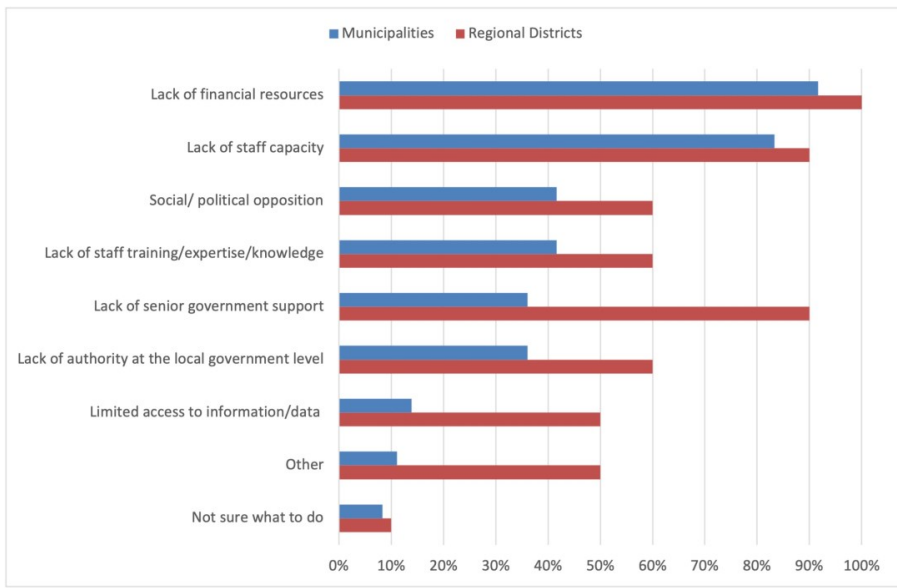

Figure 12. Climate change mitigation barriers.

In terms of capacity, the majority of municipalities and regional districts do not have dedicated staff working on climate issues. Only $32 \%$ of municipalities and $40 \%$ of regional districts indicated that they have dedicated climate staff. Although the majority of municipalities do not have dedicated climate staff, four small municipalities $(<5,000$ people) do: Tofino, Ucluelet, Highlands, and Sechelt Indian Government District. Larger municipalities $(>20,000$ people) are more likely to have climate staff, with the four largest municipalities indicating that they have dedicated

CIP-ICU \& ACUPP-APUCU staff. Regional districts with climate staff indicated they have between one to four staff.

Multiple respondents commented that although they may or may not have staff that work solely on climate change, many staff work part time on climate change issues as it relates to their mandates, and climate change is integrated throughout several departments. Most municipalities (79\%) and all regional districts employ planners, with large municipalities tending to have the highest number of planners. The municipalities with no planners are all small municipalities located in the northern part of Vancouver Island. Regional districts have an average of six planners.

Besides funding and capacity issues, small municipalities face additional barriers including lack of expertise and limited data. Small $(<5,000$ people) and mid-sized (5,000-20,000 people) municipalities were more likely to choose these options, with lack of staff training, expertise, and knowledge being the third largest barrier among small municipalities (63\%). In contrast, no large municipalities $(>20,000$ people) chose lack of expertise/training or limited access to information as barriers.

Regional districts also tend to face additional barriers as compared to municipalities, struggling with limited authority and lack of senior government support. Nearly all (90\%) regional districts selected lack of senior government support, while only $36 \%$ of municipalities face this barrier.

The COVID-19 crisis has added to the challenges faced by local governments. Open-ended responses from survey respondents indicated that staff capacity and funding issues are magnified; there is less ability for public engagement; communities are experiencing decreased transit ridership; civic projects have been delayed, and financial challenges may delay residential building retrofits. The following quotes illustrate some of these issues:

"It will change the way we engage with the public, funding for climate action might become more scarce if funding is needed to 
A case for regional climate planning in the Vancouver Island and Coastal Communities region

respond to COVID. Public support for climate change measures might be more challenged than usual if they perceive the funds better spent elsewhere." - Victoria.

"It has already delayed progress and the financial uncertainty has hindered the potential to allocate funds on these activities. Ability to take action has been delayed. Rules around community meetings make it harder to interact with citizens." - North Saanich.

\subsection{Climate change adaptation}

Similar to mitigation, municipalities and regional districts are overall highly supportive of taking action to help their communities adapt to climate change, and almost all have adaptation policies in place. Some of the top priorities for climate change adaptation mentioned in open-ended comments included emergency management planning, land use planning, infrastructure upgrades, forest management and conservation, watershed management, asset management, water conservation, urban forests, food security and local food production, air quality, and planning for sea level rise.

All regional districts and all but three municipalities have adaptation policies. Emergency management planning is the most frequently implemented adaptation policy in municipalities (77\%) and regional districts (100\%) (Figure 13). Other policy areas prioritized by municipalities include storm water management $(69 \%)$, public communication $(60 \%)$, and flood plain regulations (57\%). In

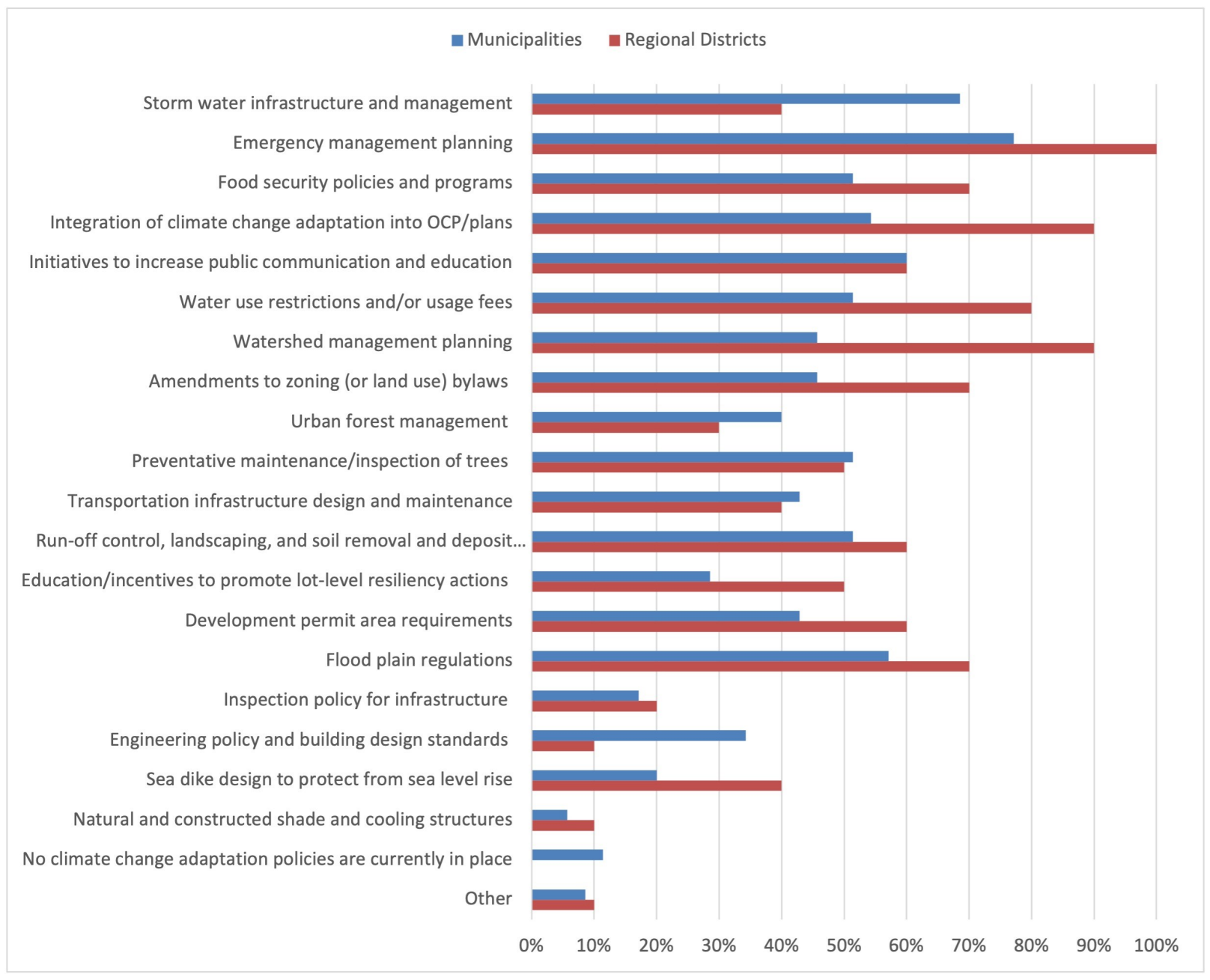

Figure 13. Adaptation policies currently implemented in municipalities and regional districts. 
regional districts, other top policies include watershed management planning $(90 \%)$, integration of adaptation in OCPs $(90 \%)$, and water use restrictions $(80 \%)$. Respondents also indicated "other" adaptation policies outside of those listed, including sea level rise interventions other than sea dikes, natural asset management strategy, groundwater protection, and revegetation for dying trees. Respondents noted that some adaptation policies are under development but not yet implemented.

There are geographic differences in the types and average number of adaptation policies. Municipalities in the North Island tended to have the fewest policies, with an average of five each, although Campbell River, the sole large municipality in this sub-region, had among the highest number of policies of any municipality. The most frequently implemented policies in the North Island included emergency management planning $(78 \%)$, storm water management $(56 \%)$, and watershed management planning (44\%). In the Central Island, there was an average of nine policies per municipality. The most frequent policies included water use restrictions $(73 \%)$, flood plain regulations (73\%), food security programs, emergency management planning, and integration of policies into the OCP (64\% each). Municipalities in the South Island had an average of 11 policies each. The most frequently implemented policies in this sub-region included public communication (92\%), emergency management planning, stormwater management, and preventative maintenance and inspection of trees ( $83 \%$ each). Finally, municipalities in the Coast sub-region had the highest average number of adaptation policies, with 12 per municipality. Top policies in this area included emergency management planning, stormwater management, transportation infrastructure, urban forest management, and integration of policies into OCP (100\% each).

The average number of policies also varies by municipality size. As with mitigation, medium (5,000-20,000 people) and large municipalities $(>20,000$ people) tend to have more adaptation policies in place compared with smaller municipalities $\quad(<5,000 \quad$ people $)$ Small municipalities averaged six adaptation policies each, mid-sized municipalities averaged ten each, and large municipalities averaged 13 each. There was less of a difference apparent between the largest urban municipalities and other large municipalities as the average number of adaptation policies for these three municipalities was the same as the overall large municipality average, unlike the case with mitigation policies where the three largest urban municipalities had a higher average number of policies. Campbell River and Gibsons had the highest number of policies at 18 each. The three municipalities that indicated they had no adaptation policies were all small municipalities, located in either the North or Central Island areas.

There are some differences in the types of policies most frequently implemented among different sized municipalities (Figure 14). In small municipalities, the most frequent adaptation policies included emergency management planning (73\%), storm water management (43\%), and public communication (43\%). In mid-sized municipalities, the most frequent policies included storm water management $(86 \%)$, preventative maintenance and inspection of trees (79\%), and emergency management planning (71\%). In large municipalities, the top policies included emergency management planning, run-off control, landscaping, and soil removal and deposit requirements, and food security programs (100\% each).

Support for adaptation policies varies (Figure 15). In municipalities, the most supported policies included storm water management (77\%), emergency management planning (71\%), and food security programs $(71 \%)$. In regional districts, the policies with the most support included emergency management planning $(100 \%)$, integration of adaptation into OCPs (100\%), and lot level resiliency $(90 \%)$. One respondent noted that it is very difficult to gauge community support for the various policy options. Also, it was noted that in the case of regional districts, support can vary widely between communities. 


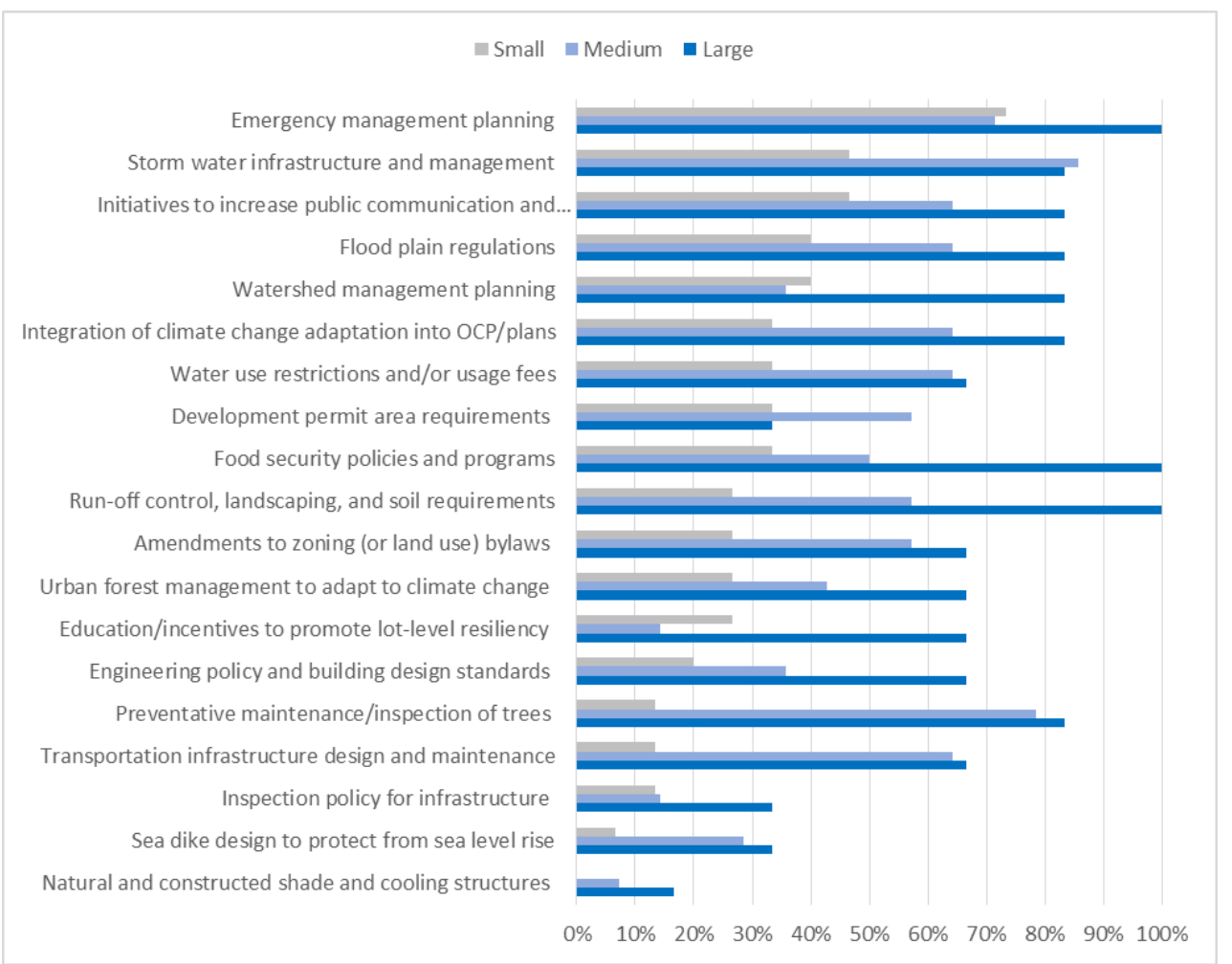

Figure 14. Adaptation policies by municipality size.

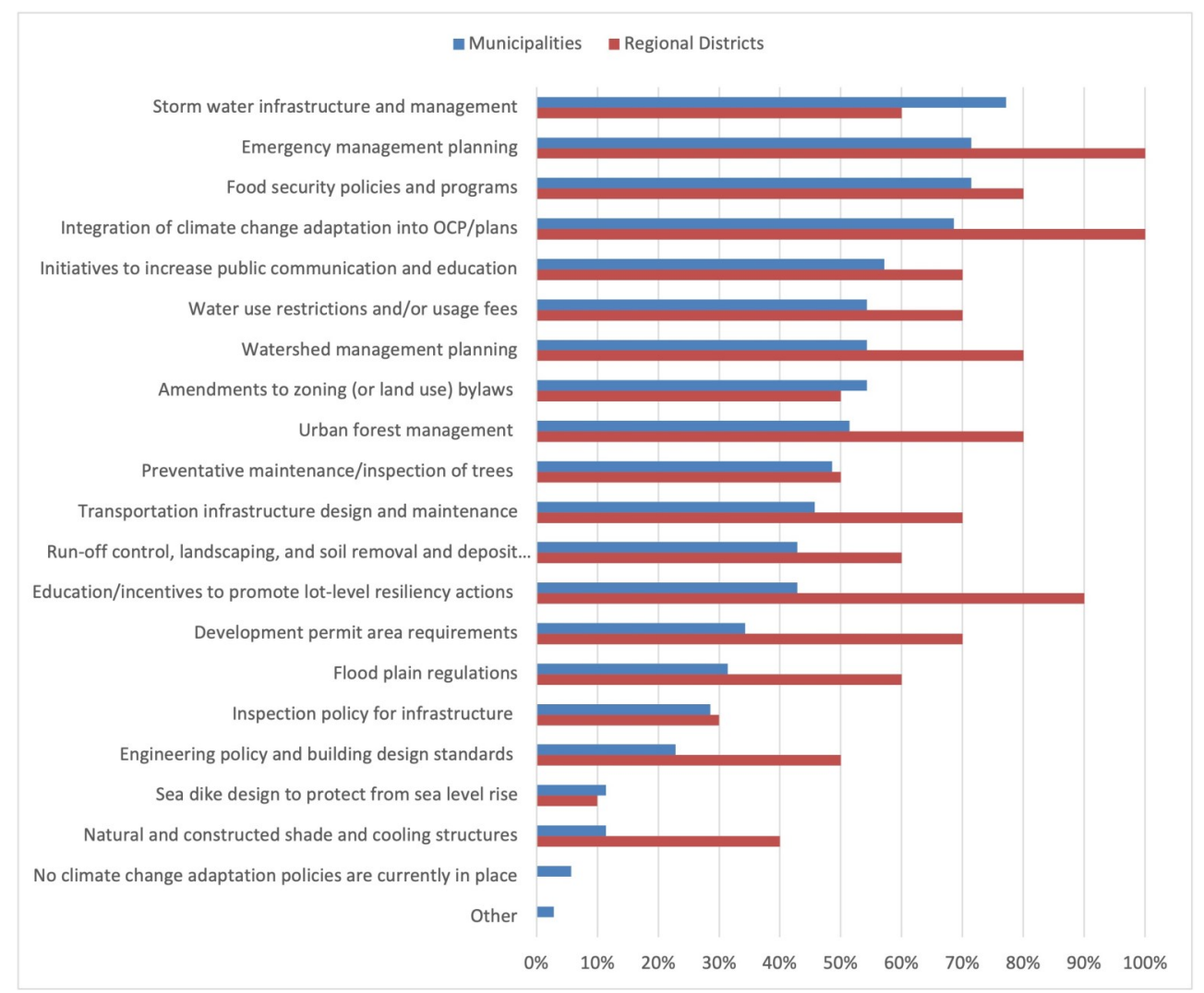

Figure 15. Support for climate change adaptation policies. 
Despite high levels of support for climate change adaptation, local governments face a number of barriers to action, with lack of financial resources indicated as the top barrier for both municipalities (94\%) and regional districts (100\%) (Figure 16). As described by one respondent:

"Policy implementation is not an issue. Lack of financial resources is." - Campbell River.

The second major barrier for municipalities is lack of staff capacity $(83 \%)$. Regional districts tend to face more barriers to adaptation compared to municipalities, with lack of senior government support $(90 \%)$, lack of staff capacity $(80 \%)$, lack of authority $(70 \%)$, and political/social opposition $(70 \%)$ as other key barriers. As discussed in the previous section on mitigation, in terms of capacity most municipalities and regional districts do not have dedicated climate staff, though the majority do have planners. Staff responsible for implementing policies related to adaptation may be spread through various departments, as adaptation measures can be broad and can vary considerably depending on the needs of each individual community. Respondents commented that climate change work is integrated throughout departments as it relates to their mandates. One respondent summed up the challenges related to lack of capacity:

"Our staff is at capacity with existing work. We need more staff to manage new projects such as climate adaptation planning or even to finish the work on the list now." Cumberland.

Smaller communities face additional challenges. Lack of staff training, expertise, and knowledge was the third largest barrier to adaptation for municipalities overall (46\%), but similar to mitigation, lack of staff expertise was much more of an issue for smaller municipalities, with no large municipalities indicating this barrier. Regional districts also struggle with lack of staff expertise $(60 \%)$, along with limited access to information/ data $(50 \%)$. The following quotes from respondents speak to some of these challenges:

"Generally there is a greater understanding of climate mitigation combined with better data collection, indicator sets, globally consistent methodologies and well researched strategies. This is lacking when it comes to climate adaptation." - Saanich.

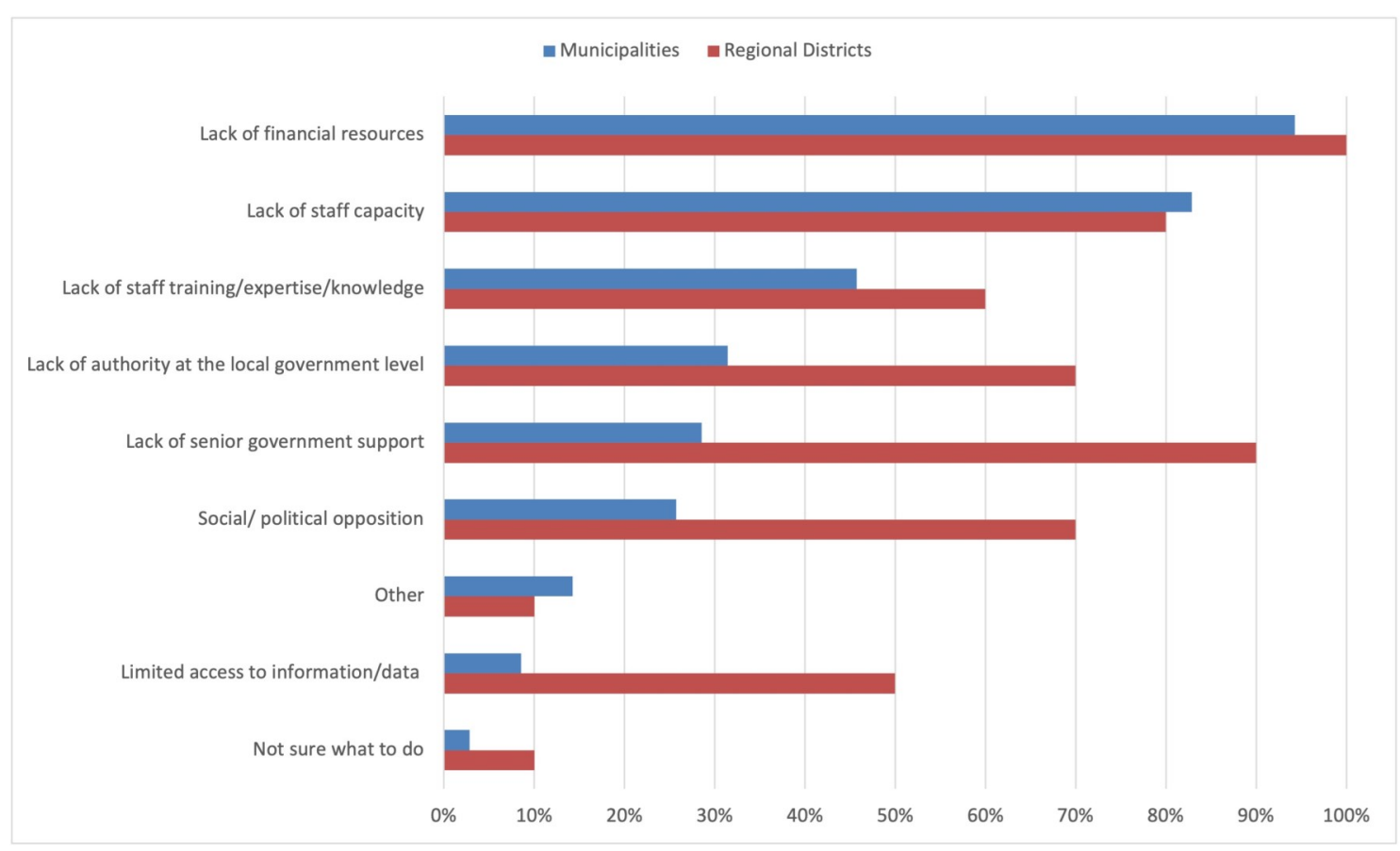

Figure 16. Climate change adaptation barriers. 
A case for regional climate planning in the Vancouver Island and Coastal Communities region

"Adaptation [is] not framed as a political priority from senior governments. No authority for systematic implementation of a regional approach to land use, transportation or infrastructure planning." - Capital Regional District.

"Green space protection faces political opposition by landowners, developers. Groundwater and multi-family rainwater catchment for potable purposes face regulatory barriers and complications. Very limited local financial capacity a barrier to new firehall and water/sewage treatment infrastructure. Greater senior government regulatory and financial support for climate adaptation initiatives needed." - Islands Trust.

"Electoral areas cannot implement tree by laws but they are becoming increasingly important [with regard to] protecting water supply." - Cowichan Valley Regional District.

While the major climate change adaptation barriers are similar to the barriers to mitigation, there are specific adaptation challenges related to lower overall understanding, challenges communicating the issues, opposition, and limited regulatory authority. As discussed with respect to climate change mitigation, the COVID-19 crisis has magnified the challenges faced by local governments. In terms of adaptation, COVID-19 may result in further reduced staffing capacity, funding challenges, and project delays.

\subsection{Climate change opportunities}

Despite the multiple barriers to climate action, respondents identified opportunities related to the climate crisis. Almost half (49\%) of municipalities see new opportunities for their community as the climate changes; another $17 \%$ answered "maybe." Among regional districts, $70 \%$ anticipate new opportunities and 30\% answered "maybe." Some examples of opportunities mentioned by respondents include building a circular economy with new sectors and jobs, benefits to tourism and agriculture including an extended growing season, telecommuting opportunities, and increased migration to small communities, such as those in the VICC region. Some of the open-ended comments illustrate future opportunities:

"Green growth - We are seeing a lot of redevelopment on our coastline and there is an opportunity to build back better." - Comox Valley Regional District.

"Economic development shaped around climate action and the opportunity to attract new investment, businesses and jobs to our community." - Esquimalt.

"New jobs in dealing with water conservation/green building/tourism." Sechelt.

"Clean energy projects, utilization of woodwaste, remote working from home for knowledge industries." - Regional District of Mount Waddington.

Several municipalities mentioned the attractiveness of smaller, safe, and/or rural communities in the future:

"Smaller communities because of livability will attract more jobs and investments." Nanaimo.

"[We are] already seeing a migration of people to what is perceived as a fairly resilient, safe community for food production, telecommuting." - Powell River.

"Rural areas have the potential to be attractive for city workers for health reasons (i.e. air quality)." - Ucluelet.

In addition to migration, increased tourism and an extended tourist season was one of the potential opportunities mentioned by respondents, including the following comment about the potential to become a destination as a learning centre for sharing knowledge: 
"We think we could be a great learning center for climate change adaptation, particularly around indigenous knowledge and practice (worldview) sharing as our collaborations with indigenous community members grows. We have a large number of very active climate change scientists, activists and educators working to develop this type of edutourism." Islands Trust.

The COVID-19 crisis has created additional challenges for local governments but also potentially presents opportunities:

"Remarkable response to COVID by all levels of government and by the public suggests we are capable of rising to the climate challenge. COVID has reinforced concerns about and is encouraging changes to address selfsufficiency (e.g., reliance on imported food and tourism)." - Islands Trust.

"The speed with which all levels of government and community responded to [the COVID-19] health crisis demonstrates the possibility, should the climate emergency be considered with a similar sense of urgency. There is a substantial opportunity for investment in climate change mitigation and adaptation as part of a green economic stimulus package." - Saanich.

"It may reduce our staffing and funding capacity even further; however, it may also increase public support for active transportation measures and urban forestry improvements for social distancing reasons that would have the add on effect of climate change mitigation and adaptation." - Sidney.

\section{Discussion AND CONCLUSIONS}

Through a web-based survey of local government officials in the VICC region $(n=106)$, we have found that nearly all communities are already experiencing hazards and impacts related to changing weather patterns caused by climate change. Most expect these hazards and impacts to continue and/or worsen into the future. These findings are substantiated by numerous scientific studies on climate change and its impacts in the region. ${ }^{1}$ Moreover, most municipalities and regional districts are overwhelmingly supportive of climate action: $100 \%$ of local governments surveyed reported that climate change mitigation and adaptation are either important or somewhat important to their community. There is widespread support for these policies and the vast majority of municipalities and all regional districts have already implemented policies related to climate change mitigation and adaptation, with the numbers and types of policies varying by geography and by size of municipality. While the number of mitigation and adaptation policies tends to be higher in larger communities, our results do not suggest that a higher number of policies corresponds with their effectiveness in addressing climate change mitigation and adaptation. Instead, the relative number of policies may indicate administrative capacity differences across VICC communities.

Despite these high levels of support for climate action in the region, local governments face multiple barriers, particularly a lack of senior government support, resources, authority, and staff capacity. These findings echo that of similar studies on the barriers to local action on climate change adaptation and mitigation (Burch, 2010; Oulahen et al., 2018). Our research has been undertaken to support a new VICC-wide climate planning initiative which is presently conducting outreach and dialogue to build buy-in and develop a vision of what a regional climate plan could achieve to build capacity and lend collective urgency to climate actions (see Vancouver Island and Coastal Communities (2021) for draft climate action goals). Thus, this project is now at a deliberative turn, which is a critical aspect of climate planning (CIP, 2018).

There are several limitations to our research. First, there are potential biases that might have affected the answers provided by respondents. Both elected officials and relevant staff within municipalities and regional districts were invited to participate, and it is possible that biases related to an individual's role 
within the organization might have influenced their answers. Though respondents were asked to provide answers on behalf of their local government based on their professional or elected role, rather than personal opinions, there might also have been some degree of personal bias in the responses, especially if a local government does not have a clear and uniform vision for climate action. Survey-based responses might have also been affected by a social desirability bias, especially in relation to support for climate action and policies. Results might have been influenced by a questionnaire design bias, as how the questions were framed and the ordering of questions might have potentially influenced how respondents answered the survey. Varying levels of knowledge might also have been a source of bias in the survey results. Finally, some survey questions required making an assessment on behalf of the whole community (e.g., assessing community support for various policies). Citizens in the community may think differently, and in fact, some respondents did point out that gauging community support can be challenging. In addition to the potential biases, a further limitation of the analysis relates to the study design. As this research was an exploratory study, the survey was designed to gather information and not to test a specific conceptual framework. Further research is needed to identify causal linkages between the identified barriers and climate actions, as well as impacts of actions on mitigating and adapting to hazards and impacts. It would be particularly interesting to investigate how the higher number of policies in larger municipalities translates into their effectiveness in reducing GHG emissions and adapting to climate change.

Despite these limitations, our study makes an important contribution to understanding the various climate impacts and policy priorities using an empirically novel survey-based approach to collecting primary data from government 'elites.' The findings point to a major rationale for regional climate planning in VICC and other regions of Canada. Community partnerships and regional planning processes can help overcome the main barriers faced by communities by enabling capacity

CIP-ICU \& ACUPP-APUCU building, knowledge and resource sharing (Bednar et al., 2018; Giest \& Howlett, 2013; Gore, 2010). This is particularly important in geographies such at the VICC where there is a large share of small and rural communities. Smaller and more remote municipalities have far less internal capacity in terms of data and expertise. Rural-rural and ruralurban partnerships could facilitate shared expertise and even joint infrastructure planning and procurement (Dale et al., 2020). Regional climate planning can also help communities prepare strong and consistent policy proposals for presentations to upper levels of government. Through collaborative planning processes, communities have a potential to accelerate the implementation of effective climate policies to build essential low-carbon infrastructure and better adapt to localized climate change impacts (Coen et al., 2020; OECD, 2017).

The scale of the VICC regional climate strategy initiative is unique in British Columbia: it will be an important case to follow as the plan is developed. Nascent efforts to adopt regional climate actions in VICC highlight the potential of bottom-up collaborative efforts to catalyse climate action and coordinate planning. Future regional planning steps should build on the survey results to formally engage with First Nations communities, and develop alternative governance structures to facilitate regional collaboration and climate planning. Senior governments can help the region and its communities achieve climate success through complementary fuel-switching policies (Jaccard et al., 2019). Future areas of research might explore how upper-level governments can structure incentives for more effective regional and multilevel governance coordination, including ruralurban and rural-rural partnerships and complementary senior-level policy, and evaluate its potential. Specifically, this research could address the potential for simultaneous horizontal collaborations between neighbouring jurisdictions and vertical collaborations with senior levels of government. This topic is ripe for comparative policy learning. 


\section{ACKNOWLedgments}

We gratefully acknowledge the support of the Pacific Institute for Climate Solutions to conduct this research. We would like to thank three Vancouver Island Mayors, Lisa Helps of Victoria, Michelle Staples of Duncan and Josie Osborne of Tofino, and representatives from each of the regional districts on the island and Sunshine Coast, and Dr. Astrid Brousselle, Dr. Tara Ney and Kimberly Harrison from the University of Victoria who have contributed to the development of the research idea and reviewed draft versions of our results.

\section{Corresponding Author}

Ekaterina Rhodes iD

School of Public Administration \& Institute for Integrated Energy Systems, University of Victoria PO Box 1700 STN CSC, Victoria, BC V8W 2Y2 Canada

Email: krhodes@uvic.ca

Phone: 250-721-8071

\section{REFERENCES}

AVICC. (2020). AVICC - Association of Vancouver Island and Coastal Communities. Retrieved March 16, 2020.

BC Ministry of Environment. (2016). Indicators of Climate Change for British Columbia, 2016 Update.

Bednar, D., Raikes, J., \& McBean, G. (2018). The governance of climate change adaptation in Canada. Toronto, ON: Institute for Catastrophic Loss Reduction.

Birkmann, J., Garschagen, M., Kraas, F., \& Quang, N. (2010). Adaptive urban governance: New challenges for the second generation of urban adaptation strategies to climate change. Sustainability Science, 5(2), 185-206. https:// doi.org/10.1007/s11625-010-0111-3

Burch, S. (2010). Transforming barriers into enablers of action on climate change: Insights from three municipal case studies in British Columbia, Canada. Global Environmental Change, 20(2), 287-297. https:// doi.org/10.1016/j.gloenvcha.2009.11.009

Canadian Institute of Planners (CIP). (2018). Policy on Climate Change Planning. Retrieved from

Capital Regional District. (2017). Regional Climate Action Strategy. Retrieved from

City of Barrie. (2017). Climate Change Adaptation Strategy.

City of Campbell River. (2020). Climate Action.

City of Nanaimo. (2012). Community Sustainability Action Plan.

City of Victoria. (2018). Climate Leadership Plan.

CivicInfoBC. (2020). People.

Coen, D., Kreienkamp, J., \& Pegram, T. (2020). Global Climate Governance. Cambridge, UK: Cambridge University Press. Retrieved from https:// doi.org/10.1017/9781108973250

Dale, A., Robinson, J., King, L., Burch, S., Newell, R., Shaw, A., \& Jost, F. (2020). Meeting the climate change challenge: Local government climate action in British Columbia, Canada. Climate Policy, 20(7), 866-880. https://doi.org/10.1080/14693062.2019.1651244

Denman, K.L. \& Macdonald, R.W. (2017). Ocean acidification in Canada's coastal waters: Climate change, processes and impacts. Canadian Climate Forum, 6.

Desjardins, X., \& Geppert, A. (2020). Governance Rescaling and Regional Planning in France: Is Big Really Beautiful? In V. Lingua \& V. Balz (Eds.), Shaping Regional Futures (pp. 121-132). Cham: Springer International Publishing. https://doi.org/10.1007/978-3-030-23573-4_9

District of Saanich. (2020). Climate Plan: 100\% Renewable and Resilient Saanich.

District of Ucluelet. (2019). Clean Energy for the Safe Harbour. 


\section{A case for regional climate planning in the Vancouver Island and Coastal Communities region}

Federation of Canadian Municipalities. (2009). Act Locally: The Municipal Role in Fighting Climate Change. Ottawa, ON: Federation of Canadian Municipalities.

Fisher, G. (2011). Municipal Climate Change Action Plan Guidebook. Halifax, NS: Service Nova Scotia and Municipal Relations.

Giest, S., \& Howlett, M. (2013). Comparative Climate Change Governance: Lessons from European Transnational Municipal Network Management Efforts: Comparative Climate Change Governance. Environmental Policy and Governance, 23(6), 341-353. https://doi.org/10.1002/ eet. 1628

Gore, C. D. (2010). The Limits and Opportunities of Networks: Municipalities and Canadian Climate Change Policy. Review of Policy Research, 27(1), 27-46. https:// doi.org/10.1111/j.1541-1338.2009.00425.x

Goulder, L. H., \& Parry, I. W. H. (2008). Instrument Choice in Environmental Policy. Review of Environmental Economics and Policy, 2(2), 152-174. https:// doi.org/10.1093/reep/ren005

Government of British Columbia. (2012). Preparing for Climate Change: An Implementation Guide for Local Governments in British Columbia.

Gupta, J., Leeuw, K. van der, \& Moel, H. de. (2007). Climate change: A 'glocal' problem requiring 'glocal' action. Environmental Sciences, 4(3), 139-148. https:// doi.org/10.1080/15693430701742677

Guyadeen, D., Thistlethwaite, J., \& Henstra, D. (2019). Evaluating the quality of municipal climate change plans in Canada. Climatic Change, 152(1), 121-143. https:// doi.org/10.1007/s10584-018-2312-1

Hodge, G., \& Robinson, I. M. (2017). Planning Canadian Regions. Vancouver, BC: UBC Press.

Jaccard, M., Failing, L., \& Berry, T. (1997). From equipment to infrastructure: Community energy management and greenhouse gas emission reduction. Energy Policy, 25(13), 1065-1074. https://doi.org/10.1016/S0301-4215(97)00091$\underline{8}$

Jaccard, M., Murphy, R., Zuehlke, B., \& Braglewicz, M. (2019). Cities and greenhouse gas reduction: Policy makers or policy takers? Energy Policy, 134, 110875. https:// doi.org/10.1016/j.enpol.2019.07.011

Krawchenko, T., Rhodes, K., Harrison, K., Pearce, K., Shaw, K., Brousselle, A., Ney, T., \& Mallows, C. (2020). Territorial Analysis and Survey of Local Government Priorities for Climate Action: Vancouver Island and Coastal Communities, Vancouver Island and Coastal Communities Climate Leadership Plan, Victoria, BC.

Ledda, A., Di Cesare, E., Satta, G., Cocco, G., Calia, G., Arras, F., ... De Montis, A. (2020). Adaptation to Climate Change and Regional Planning: A Scrutiny of Sectoral
Instruments. Sustainability, 12(9), 3804. https:// doi.org/10.3390/su12093804

Lubik, A., Helps, L., \& Logtenberg, R. (2020, January 16). B.C.'s local governments asking province for funding and partnership to tackle climate adaptation. Vancouver Sun.

OECD. (2017). The Governance of Land Use in OECD Countries: Policy Analysis and Recommendations. OECD. https://doi.org/10.1787/9789264268609-en

Oppenheimer, M., Campos, M., Warren, R., Birkmann, J., Luber, G., O'Neill, B., ... Hsiang, S. (2014). Emergent Risks and Key Vulnerabilities. In C. B. Field, V. R. Barros, D. J. Dokken, K. J. Mach, \& M. D. Mastrandrea (Eds.), Climate Change 2014 Impacts, Adaptation, and Vulnerability (pp. 1039-1100). Cambridge, UK: Cambridge University Press. https://doi.org/10.1017/ CBO9781107415379.024

Oulahen, G., Klein, Y., Mortsch, L., O’Connell, E., \& Harford, D. (2018). Barriers and Drivers of Planning for Climate Change Adaptation across Three Levels of Government in Canada. Planning Theory \& Practice, 19 (3), 405-421. https:// doi.org/10.1080/14649357.2018.1481993

Piatak, J. S., \& Holt, S. B. (2021). Public Service Motivation and Public Opinion: Examining Antecedents and Attitudes. Cambridge, UK: Cambridge University Press. https:// doi.org/10.1017/9781108966672

Regional District of Nanaimo. (2013). Energy and Climate Change Plans.

Robinson, P. J., \& Gore, C. D. (2005). Barriers to Canadian Municipal Response to Climate Change. Canadian Journal of Urban Research, 14(1), 102-120.

Simperler, L., Ertl, T., \& Matzinger, A. (2020). Spatial Compatibility of Implementing Nature-Based Solutions for Reducing Urban Heat Islands and Stormwater Pollution. Sustainability, 12(15), 5967. https://doi.org/10.3390/ $\underline{\text { su12155967 }}$

Sovacool, B. K., Axsen, J., \& Sorrell, S. (2018). Promoting novelty, rigor, and style in energy social science: Towards codes of practice for appropriate methods and research design. Energy Research \& Social Science, 45, 12-42. https://doi.org/10.1016/j.erss.2018.07.007

Tomaney, J., Krawchenko, T., \& McDonald, C. (2019). Regional planning and rural development. In M. Scott, N. Gallent, \& M. Gkartzios (Series Eds.), The Routledge Companion to Rural Planning (pp. 170-182). New York, NY: Routledge. https://doi.org/10.4324/9781315102375$\underline{18}$

Vancouver Island and Coastal Communities. (2021). Vancouver Island and Coastal Communities Climate Action Goals Working Draft. 
A case for regional climate planning in the Vancouver Island and Coastal Communities region

\section{APPENDix A: STUdy AREA POPUlation BY MUNiCIPALITY AND REgional DISTRICT}

\begin{tabular}{|c|c|c|c|c|}
\hline \multirow[t]{2}{*}{ Sub-region } & \multicolumn{2}{|l|}{ Regional districts } & \multicolumn{2}{|l|}{ Municipalities } \\
\hline & Name & Population & Name & Population \\
\hline \multirow[t]{9}{*}{ North } & \multirow[t]{4}{*}{ Mount Waddington } & \multirow[t]{4}{*}{11,035} & Alert Bay & 489 \\
\hline & & & Port Alice & 664 \\
\hline & & & Port McNeill & 2,337 \\
\hline & & & Port Hardy & 4,132 \\
\hline & \multirow[t]{5}{*}{ Strathcona } & \multirow[t]{5}{*}{44,671} & Zeballos & 107 \\
\hline & & & Tahsis & 248 \\
\hline & & & Sayward & 311 \\
\hline & & & Gold River & 1,212 \\
\hline & & & Campbell River & 32,588 \\
\hline \multirow[t]{13}{*}{ Central } & \multirow[t]{3}{*}{ Alberni-Clayoquot } & \multirow[t]{3}{*}{30,981} & Ucluelet & 1,717 \\
\hline & & & Tofino & 1,932 \\
\hline & & & Port Alberni & 17,678 \\
\hline & \multirow[t]{3}{*}{ Comox Valley } & \multirow[t]{3}{*}{66,527} & Cumberland & 3,753 \\
\hline & & & Comox & 14,028 \\
\hline & & & Courtenay & 25,599 \\
\hline & \multirow[t]{3}{*}{ Nanaimo } & \multirow[t]{3}{*}{155,698} & Lantzville & 3,605 \\
\hline & & & Qualicum Beach & 8,943 \\
\hline & & & Nanaimo & 90,504 \\
\hline & \multirow[t]{4}{*}{ Cowichan Valley } & \multirow[t]{4}{*}{83,739} & Lake Cowichan & 3,226 \\
\hline & & & Duncan & 4,944 \\
\hline & & & Ladysmith & 8,537 \\
\hline & & & North Cowichan & 29,676 \\
\hline \multirow[t]{12}{*}{ South } & \multirow[t]{12}{*}{ Capital } & \multirow[t]{12}{*}{383,360} & Highlands & 2,225 \\
\hline & & & Metchosin & 4,708 \\
\hline & & & View Royal & 10,408 \\
\hline & & & North Saanich & 11,249 \\
\hline & & & Sidney & 11,672 \\
\hline & & & Sooke & 13,001 \\
\hline & & & Central Saanich & 16,814 \\
\hline & & & Colwood & 16,859 \\
\hline & & & Esquimalt & 17,655 \\
\hline & & & Oak Bay & 18,094 \\
\hline & & & Victoria & 85,792 \\
\hline & & & Saanich & 114,148 \\
\hline \multirow[t]{4}{*}{ Coast } & Qathet & 20,070 & Powell River & 13,157 \\
\hline & \multirow[t]{3}{*}{ Sunshine Coast } & \multirow[t]{3}{*}{29,970} & $\begin{array}{l}\text { Sechelt Indian Govern- } \\
\text { ment District }\end{array}$ & 692 \\
\hline & & & Gibsons & 4,605 \\
\hline & & & Sechelt & 10,216 \\
\hline Total & 9 regional districts & 82,6051 & 38 municipalities & 607,525 \\
\hline
\end{tabular}

Note: Only municipalities that participated in survey study are listed. Islands Trust is not included in table as population is reported within other regional districts. Islands Trust population is 26,245 . 


\section{APPENdix B: SURVEY QUESTIONNAIRE "EXPloring POLICIES AND PRIORITIES FOR CREATING RESILIENCE IN THE VANCOUVER ISLAND AND COASTAL COMMUNITIES REgION."}

*1. Selecting the "yes" button below indicates that you understand the above conditions of participation in this study and that you have had the opportunity to have your questions answered by the researchers.

Yes (I consent to the aforementioned terms of the survey)

No (I do not consent to the terms of the survey)

\section{Part One: Overview of your Community}

Please fill out the survey in your formal role as staff or representative of a local government or regional district. Please do not offer personal opinions. Given that the survey is distributed to multiple staff and officials in your local government or regional district, it is acceptable to skip questions that others will be better placed to answer.

\section{Respondent identification}

First and last name:

3. Local government name (or electoral district name if no local government in the district):

4. Position (if you serve multiple roles, please identify what role you are answering the survey from):

5. How many staff work in your local government?

6. Does your local government have dedicated staff working on climate change related issues?

Yes

No

If yes, how many?

7. Does your local government employ planners?

Yes

No

If yes, how many?

8. Does your local government have a strategic climate plan? Yes

No

Don't know

9. What are the most valuable natural resources in your community from the ecological preservation perspective? List up to three natural resources (e.g., clean groundwater, shorelines, vegetation for slope stability, coastal Douglas fir ecosystem)

Resource \#1

Resource \#2

Resource \#3

10. What are the most valuable natural resources in your community from the economic development perspective? List up to three natural resources.

Resource \#1
Resource \#2

Resource \#3

11. Is Indigenous knowledge included in analysis and decision making in your local government?

12. How does your local government work with First Nation communities on climate change issues (if at all)?

13. What motivates (or would motivate) your local government to act on climate change?

Part Two: Climate Change Mitigation

"Climate change mitigation" refers to efforts to reduce greenhouse gas emissions in your entire community.

14. Overall, how important is climate change mitigation to your community?

Important

Somewhat important

Not important

15. On average, how supportive is your community of implementing climate change mitigation policies?

Supportive

Somewhat supportive

Not supportive

16. What are the top priorities for action and investment in your community with respect to climate change mitigation? (Examples might include: infrastructure upgrades, green infrastructure, land use planning, public transit, pedestrian and/or cycling infrastructure, urban forests and conservation, civic building standards, fleet management, air quality planning)

Priority \#1

Priority \#2

Priority \#3

17. Please indicate the main policy actions that your local government has taken/implemented to address climate change mitigation. Please check all that apply and/or indicate other policies not listed below.

Carbon offsets for GHG emissions in government buildings and fleet

GHG mitigation in government buildings and fleet

Regulations for energy efficient new construction

Development permit area requirements (e.g., energy and water conservation, green infrastructure requirements)

Amendments to zoning bylaws and/or development incentive programs to increase density, mixed use, and infill development

Cost charge reductions for low-carbon developments 


\section{A case for regional climate planning in the Vancouver Island and Coastal Communities region}

Rebates/incentives for home energy audits, energy efficient retrofits, and/or installation of alternative energy technology

Educational programs and information to promote energy efficiency awareness and/or alternative energy to homeowners and/or businesses

Improvements to public transit

Pedestrian/cycling infrastructure improvements (e.g., sidewalks, bike lanes, etc)

Parking restrictions/fees

Incentives and infrastructure for low or zero emission vehicles (e.g., EV charging stations, priority parking, etc)

Anti-idling bylaws

Policies to prevent conversion of forest land to non-forest land

Carbon sequestration and emission reduction on agricultural land

Urban forest management to reduce carbon emissions

Watershed management planning

Policies to increase recycling and/or divert organic material (composting)

Landfill gas capture

Convert non-diverted waste to energy

Incentives to reduce waste through solid waste fee structures

No climate change mitigation policies are currently in place

Other (please specify)

18. Among the following climate change mitigation policies/ actions, which ones would have the greatest support from your community? Please check all policies that are likely to have the greatest support (or the lowest opposition).

Carbon offsets for GHG emissions in government buildings and fleet

GHG mitigation in government buildings and fleet

Regulations for energy efficient new construction

Development permit area requirements (e.g., energy and water conservation, green infrastructure requirements)

Amendments to zoning bylaws and/or development incentive programs to increase density, mixed use, and infill development

Cost charge reductions for low-carbon developments

Rebates/incentives for home energy audits, energy efficient retrofits, and/or installation of alternative energy technology

Educational programs and information to promote energy efficiency awareness and/or alternative energy to homeowners and/or businesses

Improvements to public transit

Pedestrian/cycling infrastructure improvements (e.g., sidewalks, bike lanes, etc.)

Parking restrictions/fees

Incentives and infrastructure for low or zero emission vehicles (e.g., EV charging stations, priority parking, etc.)

Anti-idling bylaws

Policies to prevent conversion of forest land to non-forest land

Carbon sequestration and emission reduction on agricultural land

Urban forest management to reduce carbon emissions

Watershed management planning

Policies to increase recycling and/or divert organic material (composting)

Landfill gas capture

Convert non-diverted waste to energy

Incentives to reduce waste through solid waste fee structures

I don't know

Other (please specify)

19. Are climate change mitigation strategies reflected in your community's Official Community Plan?

Not integrated - no stand alone plan

Not integrated - have a stand alone plan

Integrated comprehensively across the policies and objectives within the OCP and mainstream associated action throughout all guidelines and regulations.

Used to frame specific climate change adaptation objectives to advance climate change assessment and planning, and/or to modify specific policies and objectives to incorporate adjustments to climate change impacts

20. What are the key challenges preventing climate change mitigation in your community? Please select all responses that apply.

Lack of authority at the local government level

Lack of staff training/expertise/knowledge

Lack of staff capacity

Lack of financial resources

Limited access to information/data on climate change mitigation

Social/ political opposition

Lack of senior government support

Not sure what to do

Other (please specify)

21. What are the next climate change mitigation policies your local government would like to implement but cannot? What barriers are they facing to implementation?

\section{Part Three: Climate Change Adaptation}

"Climate change adaptation" refers to efforts to adapt to existing and expected impacts of climate change.

22. Overall, how important is climate change adaptation to your community?

Important

Somewhat important

Not important

23. On average, how supportive is your community of

implementing climate change adaptation policies?

Supportive

Somewhat supportive

Not supportive 


\section{A case for regional climate planning in the Vancouver Island and Coastal Communities region}

24. What are the top priorities for action and investment in your community with respect to climate change

adaptation? (Examples might include: infrastructure upgrades, green infrastructure, land use planning, emergency

management planning, urban forests and conservation, civic

building standards, air quality planning)

Priority \#1

Priority \#2

Priority \#3

25. Please indicate the main policy actions that your local government has taken/implemented to address climate change adaptation. Please check all that apply and/or indicate other policies not listed below.

Amendments to zoning (or land use) bylaws to adapt to climate change impacts

Development permit area requirements to adapt to climate change impacts

Flood plain regulations

Run-off control, landscaping, and soil removal and deposit requirements

Emergency management planning

Urban forest management to adapt to climate change impacts

Watershed management planning

Transportation infrastructure design and maintenance

Sea dike design to protect from sea level rise

Integration of climate change adaptation into Official Community Plan and other plans

Initiatives to increase public communication and education (e.g., about road conditions/safety during weather events, etc.)

Food security policies and programs

Storm water infrastructure and management

Preventative maintenance/inspection of trees to reduce damage caused by extreme weather events

Requirements for natural and constructed shade and cooling structures on public and private property

Engineering policy and building design standards to reflect climate change impacts and projections

Inspection policy for infrastructure to identify damage from extreme weather events

Water use restrictions and/or usage fees

Education and/or incentive programs to promote lot-level resiliency actions and storm water management (e.g., green roofs, shade structures, rain gardens, rain barrels)

No climate change adaptation policies are currently in place

Other (please specify)

26. Among the following climate change adaptation policies/ actions, which ones would have the greatest support from your community? Please check all policies that are likely to have the greatest support (or the lowest opposition).

Amendments to zoning (or land use) bylaws to adapt to climate change impacts

Development permit area requirements to adapt to climate change impacts

Flood plain regulations
Run-off control, landscaping, and soil removal and deposit requirements

Emergency management planning

Urban forest management to adapt to climate change impacts

Watershed management planning

Transportation infrastructure design and maintenance

Sea dike design to protect from sea level rise

Integration of climate change adaptation into Official Community Plan and other plans

Initiatives to increase public communication and education (e.g., about road conditions/safety during weather events, etc.)

Food security policies and programs

Storm water infrastructure and management

Preventative maintenance/inspection of trees to reduce damage caused by extreme weather events

Requirements for natural and constructed shade and cooling structures on public and private property

Engineering policy and building design standards to reflect climate change impacts and projections

Inspection policy for infrastructure to identify damage from extreme weather events

Water use restrictions and/or usage fees

Education and/or incentive programs to promote lot-level resiliency actions and storm water management (e.g., green roofs, shade structures, rain gardens, rain barrels)

I don't know

Other (please specify)

27. Are climate change adaptation strategies reflected in your community's Official Community Plan?

Not integrated - no stand alone plan

Not integrated - have a stand alone plan

Integrated comprehensively across the policies and objectives within the OCP and mainstream associated action throughout all guidelines and regulations.

Used to frame specific climate change adaptation objectives to advance climate change assessment and planning, and/or to modify specific policies and objectives to incorporate adjustments to climate change impacts

28. What are the key challenges preventing climate change adaptation in your community? Please select all responses that apply.

Lack of authority at the local government level

Lack of staff training/expertise/knowledge

Lack of staff capacity

Lack of financial resources

Limited access to information/data on climate change adaptation

Social/ political opposition

Lack of senior government support

Not sure what to do

Other (please specify) 


\section{A case for regional climate planning in the Vancouver Island and Coastal Communities region}

29. What are the next climate change adaptation policies your local government would like to implement but cannot? What barriers are they facing to implementation?

\section{Part Four: Past Hazards}

30. What are the top five Hazards facing your community? Please select up to FIVE hazards most critical to your community. ("Hazard" refers to the potential occurrence of a natural or human-induced physical event or trend or physical impact that may cause loss of life, injury, or other health impacts, as well as damage and loss to property, infrastructure, livelihoods, service provision, ecosystems, and environmental resources.)

Drought

Extreme rainfall (amount, duration and/or intensity)

Extreme wind

Flooding (freshwater)

Coastal storm surge

Hurricane and/or hurricane force winds (wind speeds $>118 \mathrm{~km} / \mathrm{h}$ )

Extreme heat wave

Reduced snowpack

Landslides

Wildfires

Sea level rise

Ocean acidification

Not applicable/no hazards

Other (please specify)

31. What kind of actions or measures (if any) were undertaken in order to address or respond to the hazardous events indicated in the previous question?

32. What impacts or adverse effects, resulting from weather events and weather patterns driven by climate change, have become issues for your community? Please select up to FIVE of the top priorities/challenges critical to your community. ("Impacts" refer to effects on natural and human systems of extreme weather and climate events and of climate change. Impacts generally refer to effects on lives, livelihoods, health, ecosystems, economies, societies, cultures, services, and infrastructure due to the interaction of climate changes or hazardous climate events occurring within a specific time period and the vulnerability of an exposed society or system.)

Water supply issues

Water quality issues

Electricity supply issues

Infrastructure failures

Regional food security issues

Pests and/or invasive species

Poor air quality

Public health impacts (other than air quality)

Impacts to tourism and/or recreation

Impacts to coastal ecosystems

Impacts to land based ecosystems

Impacts to aquatic resources and/or fisheries

Impacts to forests and/or forestry

Impacts to biodiversity

Increased demand on emergency response services
Impacts to transportation systems

Not applicable/no impacts

Other (please specify)

33. Would you like to offer any further explanation of your answers above?

34. How well prepared is your local government if such hazards or events occur again; especially if such an event becomes more frequent or severe as a result of climate change?

\begin{tabular}{|l|l|l|l|l|}
\hline $\begin{array}{l}\text { Event/ } \\
\text { hazard name }\end{array}$ & $\begin{array}{l}\text { Not } \\
\text { prepared }\end{array}$ & $\begin{array}{l}\text { Somewhat } \\
\text { prepared }\end{array}$ & Prepared & $\begin{array}{l}\text { Don't } \\
\text { know }\end{array}$ \\
\hline Hazard \#1-5 & & & & \\
\hline
\end{tabular}

35. Does your local government have the capacity/resources to manage the next hazard/event?

\begin{tabular}{|l|l|l|l|l|}
\hline $\begin{array}{l}\text { Event/hazard } \\
\text { name }\end{array}$ & $\begin{array}{l}\text { No } \\
\text { capacity/ } \\
\text { resources }\end{array}$ & $\begin{array}{l}\text { Some } \\
\text { capacity/ } \\
\text { resources }\end{array}$ & $\begin{array}{l}\text { Strong } \\
\text { capacity/ } \\
\text { resources }\end{array}$ & $\begin{array}{l}\text { Don’t } \\
\text { know }\end{array}$ \\
\hline Hazard \#1-5 & & & & \\
\hline
\end{tabular}

36. How often do these hazardous events occur?

\begin{tabular}{|l|l|l|l|l|}
\hline $\begin{array}{l}\text { Event/hazard } \\
\text { name }\end{array}$ & $\begin{array}{l}\text { Not } \\
\text { frequently } \\
\text { (once every } \\
5 \text { years or } \\
\text { less) }\end{array}$ & $\begin{array}{l}\text { Somewhat } \\
\text { frequently } \\
\text { (every year } \\
\text { on average) }\end{array}$ & $\begin{array}{l}\text { Frequently } \\
\text { (several } \\
\text { times a } \\
\text { year) }\end{array}$ & $\begin{array}{l}\text { Don't } \\
\text { know }\end{array}$ \\
\hline Hazard \#1-5 & & & & \\
\hline
\end{tabular}

37. What is the severity of the economic impacts of these events in your community?

\begin{tabular}{|l|l|l|l|l|}
\hline $\begin{array}{l}\text { Event/hazard } \\
\text { name }\end{array}$ & Low & Medium & High & $\begin{array}{l}\text { Don't } \\
\text { know }\end{array}$ \\
\hline Hazard \#1-5 & & & & \\
\hline
\end{tabular}

38. What is the severity of the environmental impacts of these events in your community?

\begin{tabular}{|l|l|l|l|l|}
\hline $\begin{array}{l}\text { Event/hazard } \\
\text { name }\end{array}$ & Low & Medium & High & $\begin{array}{l}\text { Don't } \\
\text { know }\end{array}$ \\
\hline Hazard \#1-5 & & & & \\
\hline
\end{tabular}

39. What is the severity of the social impacts of these events in your community?

\begin{tabular}{|l|l|l|l|l|}
\hline $\begin{array}{l}\text { Event/hazard } \\
\text { name }\end{array}$ & Low & Medium & High & $\begin{array}{l}\text { Don't } \\
\text { know }\end{array}$ \\
\hline Hazard \#1-5 & & & & \\
\hline
\end{tabular}




\section{A case for regional climate planning in the Vancouver Island and Coastal Communities region}

40. What is the severity of the impacts of these events on Indigenous communities in your region?

\begin{tabular}{|l|l|l|l|l|}
\hline $\begin{array}{l}\text { Event/ } \\
\text { hazard name }\end{array}$ & Low & Medium & High & $\begin{array}{l}\text { Don't } \\
\text { know }\end{array}$ \\
\hline Hazard \#1-5 & & & & \\
\hline
\end{tabular}

\section{Part Five: Future Hazards}

41. Do you think the impacts to your community identified earlier will continue into the future and become more problematic unless actions are taken to minimize their effects?

\begin{tabular}{|l|l|l|l|l|}
\hline Impact name & Yes & Maybe & No & $\begin{array}{l}\text { Don't } \\
\text { know }\end{array}$ \\
\hline Impact \#1-5 & & & & \\
\hline
\end{tabular}

42. How and why do you think climate change impacts will become more of a problem for your community over time? Please select all that apply.

Increased exposure to hazards due to expansion of development into vulnerable areas

Increased geographic area that is vulnerable or exposed to hazards (e.g., larger areas affected by coastal flooding)

Increased vulnerability due to changing demographics (e.g., aging population)

Increased exposure and/or vulnerability due growing population

Increase in impacts to already vulnerable populations

Vulnerability due to socio-economic factors

Vulnerability related to housing issues

Lack of capacity to respond to multiple or cumulative impacts

Increasing frequency and/or intensity of hazardous events

More impermeable surfaces (roads, roofs, etc.)

System failures due to aging infrastructure

System failures due to inadequate infrastructure

Not applicable (no events/ hazards)

I don't know

I don't think impacts will become more of a problem

Other (please specify)

43. Do you think your community will experience other kinds of climate related issues in the future, which have not affected you in the past?

Yes

Maybe

No

I don't know

If you answered yes or maybe, what types of climate related issues do you think will affect your community in the future?

44. What information do you need to know to be able to plan effectively for the future of your local government, with respect to the impacts and issues you have identified? Please select up to FIVE of the most important types of information needed.

CIP-ICU \& ACUPP-APUCU
Local observations and/or indigenous knowledge

Historical changes and trends

Localized climate modelling and projected scenarios

Assessment of potential community impacts

Assessment of community vulnerabilities

Risk assessment of hazards

Mapping of climate change impacts and hazards

Demographic information

Projected development

Adaptation planning information

Information related to climate change mitigation

Technical expertise to implement solutions

Community/stakeholder engagement and support

Information on partnership opportunities

Examples of what other communities are doing

I don't know

Other information (please specify):

Final Comments

45. With reference to the information identified in the previous question, do you have this information, and/or do you know where it can be obtained?

\begin{tabular}{|l|l|l|l|l|}
\hline $\begin{array}{l}\text { Type of } \\
\text { Information }\end{array}$ & Yes & Maybe & No & $\begin{array}{l}\text { Don't } \\
\text { know }\end{array}$ \\
\hline $\begin{array}{l}\text { Information } \\
\# 1-5\end{array}$ & & & & \\
\hline
\end{tabular}

46. Do you see any new opportunities for your community in the future as the climate changes?

(e.g., economic development opportunities, green growth, new economic sectors, new jobs)

Yes

Maybe

No

I don't know

If you answered yes or maybe, please describe what type of new opportunities you anticipate.

47. Will the COVID-19 crisis impact your climate change mitigation and adaptation efforts? If so, please explain how.

48. Will you be able to attend the AVICC convention on November 6, 2020, to discuss the development of the VICC Climate Leadership Plan?

Yes

No

49. Is there anything else it would be helpful for us to know about how your local government is responding to climate change? 